\title{
Oferta Pública Inicial no Brasil (2004-2006): Uma Abordagem da Avaliação através de Múltiplos e do Custo de Capital Próprio
}

\author{
Felipe Pretti Casotti* \\ Luiz Felipe Jacques da Motta**
}

\begin{abstract}
Resumo
A precificação das ações em ofertas públicas iniciais tem sido alvo de estudos em diversos países. Abordando o conceito de avaliação por múltiplos, este artigo busca verificar se as ações das empresas estavam sub-avaliadas ou super-avaliadas no momento das suas Ofertas Públicas Iniciais. São também determinados os custos de capital associados ao preço na emissão, verificando-se a diferença entre betas utilizados no modelo CAPM, no momento da IPO, e os betas reais 12 meses após a oferta. Foi utilizada uma amostra composta por empresas que abriram capital entre 2004 e 2006. Observou-se que as ações não foram sub-avaliadas, mesmo após serem observados elevados retornos iniciais. Entretanto, não há evidências estatísticas de que foram super-avaliadas. Por fim, verificou-se que os betas após 12 meses são significativamente maiores do que os betas utilizados no momento da precificação. Como esperado, o modelo CAPM determinou retornos abaixo dos retornos ocorridos após a emissão.
\end{abstract}

Palavras-chave: Apreçamento em ofertas públicas iniciais; custo de capital; múltiplos; CAPM; betas apropriados; retornos anormais.

Códigos JEL: G12.

\section{Abstract}

The pricing process of new shares in IPOs has been under study in several countries. This paper initially looks at the valuation process using multiples and seeks to classify the new shares under two categories: underpriced or overpriced at the time of the IPOs. Analysis of the cost of equity, comparing betas at the time of the offerings (usually calculated as the betas of comparable companies) and the betas of the companies after 12 months of trading, is also carried out. Companies in the sample are those that went public between 2004 and 2006. Results indicated that companies were not undervalued, even after some high shortterm returns. However there is no statistical evidence that they were overvalued. Finally, results indicated that betas after twelve months of trading are significantly higher than the comparable companies' betas used at the time of the IPOs.

\footnotetext{
Submetido em Abril de 2008. Aceito em Julho de 2008. O artigo foi avaliado segundo o processo de duplo anonimato além se de ser avaliado pelos editores. Editor principal: Ricardo P. C. Leal.

*Pontifícia Universidade Católica do Rio de Janeiro - IAG. Endereço: Rua Marques de São Vicente 225 - Gávea, Rio de Janeiro, RJ, Brasil, Telefone: (21) 9105-1194. E-mail: fcasotti@ globo.com

**Pontifícia Universidade Católica do Rio de Janeiro - IAG. Telefone: (21) 2138-9309. E-mail: felipe@iag.puc-rio.br
} 
Keywords: Pricing of IPOs; cost of equity capital; multiples; capital asset pricing model; adequate betas; abnormal returns.

\section{Introdução}

Em 25 de maio de 2004, a Natura Cosméticos S.A., empresa pertencente ao setor de cosméticos, iniciava a negociação de suas ações na Bolsa de Valores, através de uma emissão secundária. O que seria, normalmente, uma simples oferta inicial de ações, tornou-se um marco implícito no desenvolvimento do mercado de capitais no Brasil.

Um conjunto de fatores contribuiu para tal crescimento, entre os quais, estabilização político-econômica, a intensificação do ingresso de investidores estrangeiros no país, a profissionalização da Bovespa e da CVM, e a criação do Novo Mercado, incentivando a adoção de práticas de governança corporativa.

O objetivo deste artigo é estudar o mercado de emissão inicial de ações no Brasil, em anos recentes, abordando a Avaliação por Múltiplos (ou Avaliação Relativa) e o principal modelo de determinação do custo de capital próprio (CAPM), através de uma pesquisa exploratória com companhias brasileiras que realizaram Ofertas Públicas Iniciais entre maio de 2004 e junho de 2006.

Inicialmente, serão verificados os retornos anormais de curto e longo prazo para ofertas públicas iniciais recentes no Brasil. Em seguida, através da avaliação por múltiplos, verificar-se-á se as ações das empresas que abriram capital estavam sub-avaliadas ou super-avaliadas. Por fim, serão comparados os betas utilizados no modelo CAPM e os betas observados após a IPO, e os custos de capital próprio adotados, através de um modelo derivado do CAPM.

O foco da pesquisa será o conjunto de 25 empresas, pertencentes a 19 setores distintos (Classificação NAICS), ${ }^{1}$ que realizou oferta pública inicial nos últimos anos. Em virtude dos procedimentos adotados neste trabalho, também serão analisados os múltiplos das empresas concorrentes americanas. Quanto à delimitação temporal, serão analisadas empresas que realizaram IPO entre 26/05/2004 e 02/06/2006.

\section{Organização do Trabalho}

O presente artigo está organizado em oito seções. A Seção 3 é constituído pelo referencial teórico e introduz os principais conceitos a respeito de retornos anormais, custo de capital próprio e avaliação por múltiplos, apontando as definições existentes na literatura.

\footnotetext{
${ }^{1}$ North American Industry Classification System. Para maiores informações acessar: www.naics.com
} 
A Seção 4 apresenta a metodologia adotada neste artigo, definindo a estratégia de pesquisa utilizada, a elaboração do instrumento de coleta de dados, a seleção da amostra e a forma de coleta e análise dos dados. Por fim, são apresentadas as vantagens e limitações desta metodologia. Na seção 5 é realizada a análise dos resultados.

As conclusões deste artigo, as limitações e recomendações para trabalhos futuros são apresentadas na Seção 6, enquanto as duas últimas seções tratarão respectivamente das referências e dos anexos.

\section{Referencial Teórico}

\subsection{Retornos Anormais}

Os retornos de IPOs podem ser abordados de duas maneiras: retornos de curto prazo, ou retornos iniciais (short-run returns), e retornos de longo prazo (longrun returns). Enquanto os primeiros são definidos como os retornos referentes ao primeiro dia de negociação (preço de fechamento em relação ao preço estabelecido na oferta), os de longo prazo, normalmente, consideram o período de um a três anos após a emissão. (Procianoy e Cigerza, 2007).

Stoll e Curley (1970), Reilly (1993), Logue (1973), Ibbotson e Jaffe (1975) e Ibbotson (1975) apresentaram os primeiros estudos sobre underpricing $^{2}$ em IPO, ao observarem recorrentes retornos anormais (retornos acima do retorno do mercado) no primeiro dia de negociação em emissões iniciais de ações. Nos anos seguintes, o mesmo fenômeno foi observado por Tiniç (1988), Ritter (1991) e outros autores que se propuseram a realizar pesquisas sobre o tema.

Nos Estados Unidos, de acordo com Loughran e Ritter (2002), em 1980 a média de retorno do primeiro dia de IPOs foi de $7 \%$. Passou para $15 \%$ no período entre 1990 a 1998, e para 65\% no período entre 1999 e 2000.

No Brasil, Ness e Pereira (1980), Aggarwal et alii (1993) e, mais recentemente, Procianoy e Cigerza (2007) também verificaram o fenômeno de underpricing inicial.

Ritter (2006) utilizou o termo "dinheiro deixado na mesa" para descrever a situação na quais elevados retornos iniciais são obtidos por investidores em emissões iniciais. Como a empresa poderia ter cobrado mais caro pelas ações, ela acabou "deixando dinheiro na mesa" para os investidores, ou seja, deixou de captar mais recursos do que eventualmente poderia.

${ }^{2} \mathrm{O}$ estudo acerca de IPO cria a necessidade de uma breve definição sobre os termos "Underpricing”(sub-avaliação) e "Overpricing”(super-avaliação), amplamente discutidos na literatura. No caso dos retornos de curto prazo, o retorno é determinado pela diferença entre o preço de fechamento do primeiro dia de negociação no mercado secundário e o preço estipulado na oferta inicial. Ocorre "Underpricing" se o preço de fechamento for maior do que o preço inicial da oferta. A ação foi sub-avaliada e o investidor pôde obter retornos em um pequeno período de tempo. No entanto, se o preço de fechamento foi menor do que o preço inicial houve overpricing, ou seja, a ação foi super-avaliada e o investidor obteve retornos negativos. 
Apesar de terem sido verificados retornos de curto prazo bastante superiores aos retornos do mercado, em diversos países (Loughran et alii, 1994, Ljungqvist, 2004, McCarthy, 1999), os retornos de longo prazo apresentam resultados controversos (Ritter e Welch, 2002).

Stoll e Curley (1970) foram os pioneiros em verificar retornos anormais no primeiro dia em IPOs. Ao analisar 205 pequenas empresas que abriram capital nos Estados Unidos, em 1957, 1959 e 1963, foram encontrados retornos anormais de curto prazo superiores aos do índice de referência. No entanto, os retornos de longo prazo foram significativamente inferiores.

Ritter (1991) verificou retornos anormais de curto prazo para ações que estrearam na bolsa, sugerindo a sub-alvaliação ("underpricing") destas. No entanto, quando analisa no longo prazo (três anos), usando uma amostra composta por 1526 empresas que abriram capital nos Estados Unidos entre 1974 e 1985, verifica que estas podem estar sendo super-avaliadas ("overvalued"), já que apresentaram retornos abaixo dos retornos de empresas comparáveis.

Ao analisar o período de três anos após o IPO, Firth (1998) encontrou retornos próximos de zero para empresas que fizeram emissões iniciais em Singapura entre 1979 e 1992. Loughran e Ritter (1995) também verificam baixos retornos de longo prazo, ao observarem 4753 empresas que realizaram IPO entre 1970 e 1990, nos Estados Unidos. Ritter e Welch (2002), utilizando uma amostra com firmas norteamericanas que realizaram IPOs, descobriram que o retorno médio de três anos ajustado pelo mercado foi de $-23,4 \%$.

Toniato (2007), ao realizar um estudo clínico no mercado de IPO no Reino Unido, observa underpricing inicial e desempenho inferior de longo prazo das emissões novas. Em seus resultados, foram encontrados retornos de primeiro dia que variaram de 63\% a, impressionantes, 2877\%.(retornos utilizando MAARs, Market Adjusted Abnormal Returns). Os BHARs (Buy-and-Hold Adjusted Returns) foram em geral negativos, ou seja, retornos de longo prazo foram abaixo dos benchmarks. As definições de MAAR e BHAR são encontradas na subseção 4.2 adiante.

No Brasil, Procianoy e Cigerza (2007) verificaram que a média dos retornos do primeiro dia para uma amostra composta por empresas que realizaram IPO entre 2004 e 2006 foi de 7,10\%. Aggarwal et alii (1993), ao analisar as emissões de 62 empresas entre 1980 e 1990, encontraram retornos de 78,50\% (MAAR). No entanto, estes últimos autores identificaram a alta taxa de inflação do período como possível causa dos elevados retornos. Anteriormente, Ness e Pereira (1980) mediram em mais de $100 \%$ o retorno médio em excesso dos investidores, em aberturas de capital na década 70 .

Toniato (2007) consolida resultados obtidos por diversos autores em diferentes países acerca do desempenho de curto e longo prazo das IPOs. Seus resultados são mostrados nas figuras 1 e 2 abaixo. 


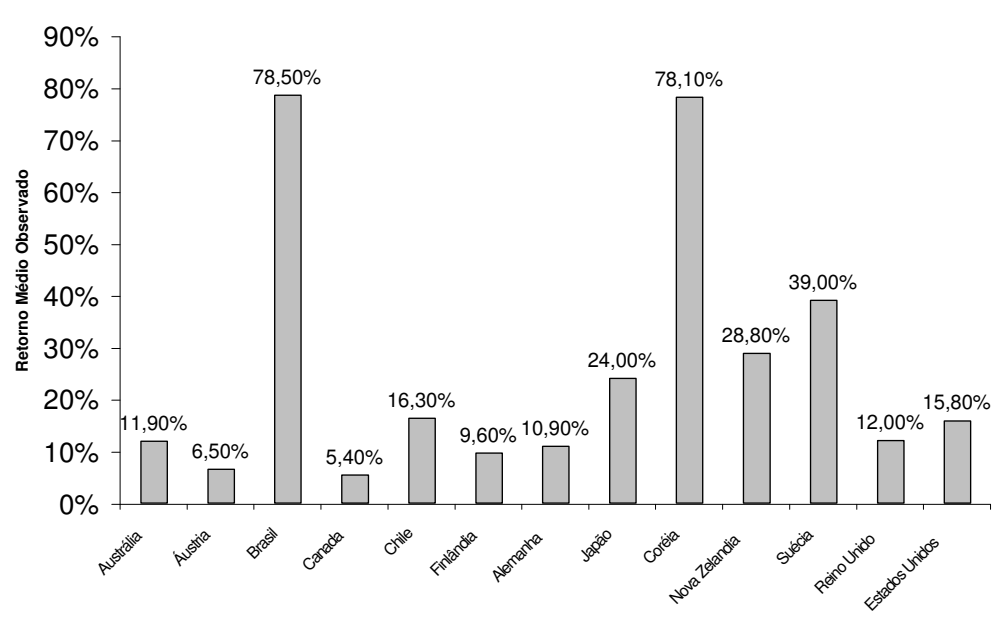

Figura 1

Evidência internacional de desempenho de IPOs no curto prazo

Fonte: Toniato (2007)

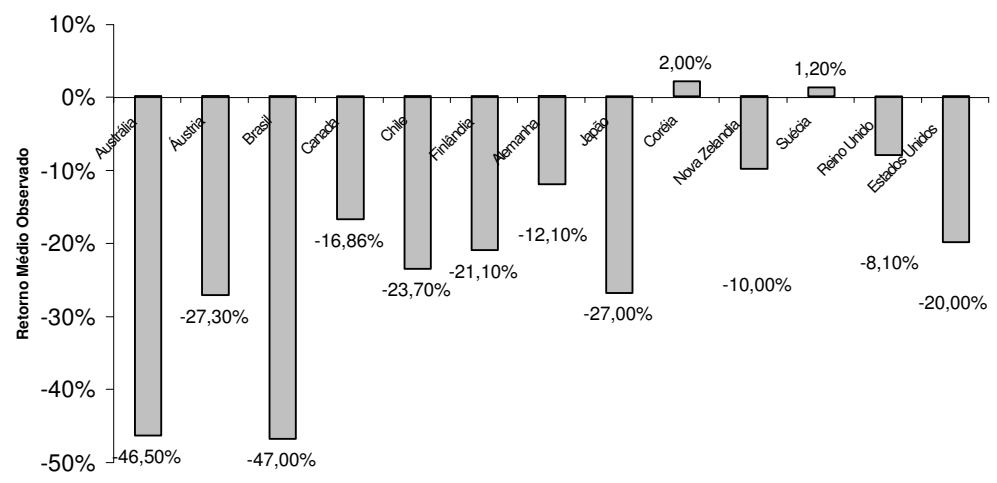

Figura 2

Evidência internacional de desempenho de IPOs no longo prazo

Fonte: Toniato (2007)

\subsection{Modelos de avaliação de empresas}

Existem três principais abordagens para avaliação de empresas. A primeira, avaliação por fluxo de caixa descontado (FCD), relaciona o valor do ativo ao valor presente dos seus fluxos de caixa esperados. A segunda, denominada avaliação relativa, estima o valor de um ativo de acordo com a precificação de ativos comparáveis relativamente a uma variável comum. A última abordagem, avaliação de 
direitos contingentes, utiliza o modelo de precificação de opções para definir o preço do ativo. ${ }^{3}$ Este artigo abordará os dois modelos mais utilizados na avaliação de empresas: o modelo de Fluxo de Caixa Descontado (FCD) e o Modelo de Avaliação Relativa, ou por Múltiplos.

\subsection{Custo de capital próprio - modelos CAPM e Goldman Sachs}

Por ser considerada a taxa de desconto utilizada no Fluxo de Caixa do acionista (FCA) e, componente determinante do Custo Médio Ponderado de Capital (WACC), o custo de capital próprio apresenta papel de destaque na precificação de ações.

O CAPM, modelo de precificação de ativos desenvolvido por Treynor (1961), Sharpe (1964), Lintner (1965) e Mossin (1966), estabelece uma relação linear entre risco e retorno. Considera que os investidores são racionais e diversificados, não correndo, portanto, o risco não sistemático (diversificável) e exigindo retorno apenas pelo risco sistemático.

Algumas ressalvas têm sido feitas quanto à utilização do modelo CAPM na determinação do custo de capital próprio de empresas que abrem capital no Brasil.

A aplicação direta deste modelo em mercados emergentes deve ser questionada, devido às premissas expostas anteriormente. Segundo Pereiro (2001), a hipótese de eficiência dos mercados deve ser debatida e a participação das bolsas de valores nos mercados emergentes tende a ser pequena em comparação ao PIB, possuindo pequeno número de empresas abertas, se comparada com países desenvolvidos. Além disso, as bolsas são altamente concentradas, o que diminui a liquidez dos papeis negociados e a capacidade de diversificação dos investidores, criando a possibilidade de manipulação de preços.

Segundo Damodaran (2003), os índices de mercado calculados em países emergentes possuem elevada concentração em poucas ações, fazendo com que a estimativa de beta das demais ações que compõem o índice seja na verdade o resultado da regressão em relação às ações que possuem grande concentração, ao invés de ser em relação a um índice que represente o mercado como um todo.

Deve-se destacar, ainda, a importância dos investidores estrangeiros nos processos de IPO no Brasil e a necessidade de se calcular um custo de capital do acionista que considere, principalmente, este participante do mercado. Desde 2004, a participação de investidores estrangeiros nos processos de abertura de capital foi expressiva e significativamente superior a de investidores locais. Isto é confirmado na Tabela 1 abaixo.

${ }^{3}$ DAMODARAN, A. Avaliação de investimentos: ferramentas e técnicas para a determinação do valor de qualquer ativo. Trad. Carlos Henrique Trieschmann e Ronaldo de Almeida Rego. Rio de Janeiro: Qualitymark, 2003. 
Tabela 1

Participação dos estrangeiros

\begin{tabular}{lcccccc}
\hline \multicolumn{1}{c}{ Empresa } & $\begin{array}{c}\text { Volume Total } \\
\text { da Distribuição }\end{array}$ & \multicolumn{2}{c}{$\begin{array}{c}\text { Volume da } \\
\text { Oferta Brasileira }\end{array}$} & \multicolumn{2}{c}{$\begin{array}{c}\text { Volume Estrangeiro } \\
\text { na Oferta Brasileira }\end{array}$} & \multicolumn{2}{c}{$\begin{array}{c}\text { Volume Estrangeiro } \\
\text { na Oferta Total }\end{array}$} \\
& $(\mathrm{R} \$)$ & $(\mathrm{R} \$)$ & $(\mathrm{R} \$)$ & Part. $(\%)$ & $(\mathrm{R} \$)$ & Part.(\%) \\
\hline Vivax Unit & $529.200 .000,00$ & $529.200 .000,00$ & $363.177 .979,50$ & 68,63 & $363.177 .979,50$ & 68,63 \\
Gafisa & $926.988 .750,00$ & $926.988 .750,00$ & $669.685 .366,50$ & 72,24 & $669.685 .366,50$ & 72,24 \\
Company & $281.600 .000,00$ & $281.600 .000,00$ & $179.150 .400,00$ & 63,62 & $179.150 .400,00$ & 63,62 \\
Copasa & $813.461 .524,00$ & $813.461 .524,00$ & $601.036 .117,50$ & 73,89 & $601.036 .117,50$ & 73,89 \\
Totvs & $460.000 .000,00$ & $460.000 .000,00$ & $319.450 .720,00$ & 69,45 & $319.450 .720,00$ & 69,45 \\
Equatorial & $540.270 .000,00$ & $540.270 .000,00$ & $414.081 .125,50$ & 76,64 & $414.081 .125,50$ & 76,64 \\
Diagnósticos da América & $662.383 .274,00$ & $662.383 .274,00$ & $562.487 .954,00$ & 84,92 & $562.487 .954,00$ & 84,92 \\
Submarino & $929.076 .920,00$ & $929.076 .920,00$ & $835.591 .265,00$ & 89,94 & $835.591 .265,00$ & 89,94 \\
Localiza & $394.039 .274,00$ & $394.039 .274,00$ & $290.025 .185,00$ & 73,6 & $290.025 .185,00$ & 73,6 \\
CSU CardSystem & $340.972 .578,00$ & $340.972 .578,00$ & $282.623 .940,00$ & 82,89 & $282.623 .940,00$ & 82,89 \\
ABnote & $480.434 .790,00$ & $480.434 .790,00$ & $385.173 .403,00$ & 80,17 & $385.173 .403,00$ & 80,17 \\
Lupatech & $452.740 .024,00$ & $452.740 .024,00$ & $351.889 .956,00$ & 77,72 & $351.889 .956,00$ & 77,72 \\
Datasul & $317.012 .508,00$ & $317.012 .508,00$ & $253.081 .800,00$ & 79,83 & $253.081 .800,00$ & 79,83 \\
GP Investments & $705.980 .848,50$ & $705.980 .848,50$ & $548.367 .703,84$ & 77,67 & $548.367 .703,84$ & 77,67 \\
Porto Seguro & $201.000 .000,00$ & $201.000 .000,00$ & $108.198 .300,00$ & 53,83 & $108.198 .300,00$ & 53,83 \\
\hline Total & $8.035 .160 .490,50$ & $8.035 .160 .490,50$ & $6.164 .021 .215,84$ & 75,00 & $6.164 .021 .215,84$ & 75,00 \\
\hline Fonte: Bovespa
\end{tabular}

Fonte: Bovespa.

Segundo Leal (2002), o CAPM doméstico simples com um fator de risco de mercado doméstico não se aplica, particularmente quando estamos tratando de empresas cujos acionistas são estrangeiros. Ao analisar o custo de capital próprio da ótica do investidor estrangeiro, ajustes devem ser realizados no modelo CAPM básico. Estes ajustes devem considerar a aversão de investidores a investimentos em países emergentes, ou que apresentem riscos soberanos mais elevados que o de seus países. É recomendado contemplar o uso de um modelo que inclua um prêmio de risco global e um prêmio de risco para o país.

Por fim, a existência de poucas empresas listadas em bolsa, no Brasil, prejudica a utilização de betas comparáveis (em relação ao índice de mercado brasileiro), alternativa comum para empresas que pretendem abrir capital. Torna-se necessário, então, utilizar betas de empresas comparáveis americanas (em relação ao S\&P 500), ajustando o modelo CAPM para tal.

Em mercados emergentes é recomendado o ajuste do CAPM pelo risco país. Segundo Minardi et alii (2007), essa metodologia é prática comum no mercado, sendo normal encontrá-la em relatórios de bancos e consultorias. Assim, a fórmula do custo do capital próprio é ajustada para:

$$
k e=r f+r p+\beta \times(E(r m)-r f)
$$


onde:

$k e=$ custo de Capital Próprio

$r f=$ taxa livre de risco americana

$r p=$ diferença entre os yields to maturity dos títulos dos governos brasileiro e americano de longo prazo, de mesma duração.

$\beta=$ beta de empresas americanas comparáveis em relação ao mercado americano $E(\mathrm{rm})=$ retorno esperado para um índice do mercado americano, estimado com base no retorno anual histórico.

$(E(r m)-r f)=$ ágio pelo risco no mercado americano ou prêmio do mercado americano.

Este modelo CAPM ajustado para o risco país é denominado "Goldman Model" ou "The Country Spread Model” (Harvey, 2001). Como os retornos exigidos para o mercado brasileiro são maiores, adiciona-se à SML (Security Market Line) o risco país, corroborando a hipótese de que os mercados não são completamente integrados. A utilização do modelo busca flexibilizar as dificuldades inerentes ao modelo CAPM simples. Ressalta-se que o modelo é determinado em dólares.

Devido a sua popularidade, o Modelo Goldman é utilizado por um grande número de bancos e consultorias e será adotado neste trabalho para calcular o custo de capital próprio de uma amostra composta por 25 empresas que abriram capital entre maio de 2004 e junho de 2006, no Brasil.

\subsection{Avaliação relativa ou avaliação por múltiplos}

Dentre os métodos de avaliação de empresa, o mais simples é a análise através de múltiplos de mercado, também conhecido como Avaliação Relativa ou Avaliação por Múltiplos. Nela, o valor de um ativo deriva da precificação de ativos comparáveis pelo uso de uma variável comum, como lucros, fluxo de caixa, valores contábeis ou receitas, criando-se índices como meio de comparação.

Segundo Kim e Ritter (1999), o uso de múltiplos é amplamente recomendado para a avaliação de IPOs. No momento da emissão, a firma e os coordenadores da oferta utilizam múltiplos para a definição do intervalo de preços. Após a avaliação, mais informações são coletadas através de uma análise da demanda e o preço final é, então, estabelecido.

Segundo Damodaran (2003), a utilização de múltiplos de empresas comparáveis pode variar do método ingênuo (utilizando médias setoriais) ao método sofisticado (modelos multivariados, onde variáveis relevantes são identificadas e controladas).

De acordo com Famá e Santiago Filho (2001), quando não existem empresas de um determinado setor negociadas em bolsa de valores, avalia-se determinada oportunidade de investimento apenas através dos múltiplos de empresas estrangeiras comparáveis. No entanto, estas práticas podem induzir a erros, pois não são levadas em conta variáveis que podem afetar o desempenho do mercado 
financeiro de determinado país. Estas variáveis, dependendo do tipo de setor analisado, podem levar em conta aspectos políticos, econômicos, de nível educacional da população, volume médio de negociação em bolsas de valores e risco-país.

Famá e Santiago Filho (2001) citam, dentre os principais múltiplos:

1) Múltiplos de Lucro:

- Preço/Lucro

- Preço/EBIT

- Preço/EBITDA

2) Valor Patrimonial:

- Preço/Valor Patrimonial

- Preço/Valor Patrimonial dos Ativos

- Preço/Custo de Reposição (Q de Tobin)

3) Receitas:

- Preço/Vendas

4) Enterprise Value:

- EV/EBITDA

- EV/Lucro

- EV/Vendas

5) Variável específica da indústria analisada: Preço/kWh, Preço/tonelada, Preço/linha telefônica, etc.

Este artigo utilizou dois múltiplos como referência: Preço/Lucro ou Price/Earnings (PE) e Valor da Firma/EBIT ou Enterprise Value/EBIT. A escolha se deve à importância e popularidade dos índices entre pesquisadores, investidores e analistas. (Damodaran, 2003). Os mesmos múltiplos foram utilizados para todas as indústrias analisadas. Liu et alii (2002) não econtraram evidências de que diferentes indústrias devem ser analisadas com diferentes múltiplos.

Quanto ao tempo dos múltiplos, Damodaran ${ }^{4}$ e Povoa ${ }^{5}$ abordam três possibilidades básicas: Múltiplo Passado, Múltiplo Corrente e Múltiplo Futuro.

- Múltiplo Passado ("past multiple”): Utiliza o preço corrente e o resultado do ano anterior

\footnotetext{
${ }^{4}$ Para maiores informações acessar www.damodaran.com

${ }^{5}$ Póvoa, A. Valuation: como precificar ações. São Paulo: Globo, 2004.
} 
- Múltiplo Corrente ("trailing multiple"): Utiliza o preço corrente e o resultado projetado para o ano corrente.

- Múltiplo Futuro ("forward multiple"): Utiliza o preço corrente e o resultado projetado para o ano posterior.

Segundo Kim e Ritter (1999) e Liu et alii (2002) a utilização de múltiplos com base em resultados projetados é mais eficiente que a baseada em resultados históricos. Muitas empresas que realizam IPO apresentam crescimento expressivo nos anos próximos à emissão, por isso, a utilização de resultados passados pode distorcer o múltiplo que realmente deve ser utilizado.

A amostra analisada neste artigo apresenta elevadas taxas de crescimento de Lucro (LL) e EBIT no período próximo a IPO, justificando a adoção da abordagem de múltiplos futuros. A Natura, por exemplo, que realizou IPO em maio de 2004, obteve lucro (dos últimos doze meses) em 2003 de $\mathrm{R} \$ 63.884 .000,00$, enquanto que em junho de 2005, apresentou lucro (dos últimos doze meses) de R\$ 334.371.000,00, ou seja, um crescimento de $423,20 \%$. Se fosse utilizado o P/L passado, o múltiplo seria de 48,84. Já, ao utilizar o múltiplo futuro, o P/L é 9,331. O crescimento nominal do lucro das outras empresas é demonstrado na Tabela 2 abaixo.

Tabela 2

Crescimento nominal do lucro líquido e EBIT da amostra

\begin{tabular}{|c|c|c|c|c|c|c|c|}
\hline Empresa & Data & $\begin{array}{c}\text { LL utilizado para } \\
\text { P/L passado }\end{array}$ & $\begin{array}{c}\text { LL utilizado para } \\
\text { P/L futuro }\end{array}$ & $\begin{array}{c}\begin{array}{c}\text { Variação } \\
(\%)\end{array} \\
\end{array}$ & $\begin{array}{l}\text { EBIT utilizado para } \\
\text { EV/EBIT passado }\end{array}$ & $\begin{array}{l}\text { EBIT utilizado para } \\
\text { EV/EBIT futuro }\end{array}$ & $\begin{array}{c}\text { Variação } \\
(\%)\end{array}$ \\
\hline Natura & $26 / 05 / 04$ & $63.884 .000,0$ & $334.371 .000,0$ & 423,40 & $260.542 .000,0$ & $439.484 .000,0$ & 68,68 \\
\hline Gol & $24 / 06 / 04$ & $113.044 .000,0$ & $356.619 .000,0$ & 215,47 & $231.526 .000,0$ & $533.362 .000,0$ & 130,37 \\
\hline ALL Amer Lat & $25 / 06 / 04$ & $10.154 .000,0$ & $148.589 .000,0$ & 1363,35 & $177.131 .000,0$ & $250.446 .000,0$ & 41,39 \\
\hline CPFL Energia & $29 / 09 / 04$ & $-297.392 .000,0$ & $1.021 .278 .000,0$ & $-443,41$ & $1.193 .927 .000,0$ & $1.943 .327 .000,0$ & 62,77 \\
\hline Grendene & $29 / 10 / 04$ & $203.221 .000,0$ & $85.401 .000,0$ & $-57,98$ & $239.004 .000,0$ & $129.980 .000,0$ & $-45,62$ \\
\hline Dasa & $19 / 11 / 04$ & $-8.482 .000,0$ & $10.157 .000,0$ & $-219,75$ & $56.015 .000,0$ & $77.136 .000,0$ & 37,71 \\
\hline Porto Seguro & $22 / 11 / 04$ & $141.059 .000,0$ & $248.657 .000,0$ & 76,28 & $-518.808 .000,0$ & $-51.820 .000,0$ & $-90,01$ \\
\hline Renar & $28 / 02 / 05$ & $1.025 .903,0$ & $-4.347 .529,0$ & $-523,78$ & $3.764 .644,0$ & $26.681,0$ & $-99,29$ \\
\hline Submarino & $30 / 03 / 05$ & $6.390 .000,0$ & $18.684 .000,0$ & 192,39 & $27.138 .000,0$ & $29.896 .000,0$ & 10,16 \\
\hline Localiza & $23 / 05 / 05$ & $102.343 .000,0$ & $92.190 .000,0$ & $-9,92$ & $176.476 .000,0$ & $215.595 .000,0$ & 22,17 \\
\hline Energias BR & $13 / 07 / 05$ & $106.875 .000,0$ & $394.667 .000,0$ & 269,28 & $548.871 .000,0$ & $893.663 .000,0$ & 62,82 \\
\hline OHL Brasil & $15 / 07 / 05$ & $25.238 .000,0$ & $104.597 .000,0$ & 314,44 & $119.029 .000,0$ & $174.582 .000,0$ & 46,67 \\
\hline Cosan & $18 / 11 / 05$ & $17.102 .000,0$ & $357.269 .000,0$ & 1989,05 & $268.270 .000,0$ & $595.703 .000,0$ & 122,05 \\
\hline Uol & $16 / 12 / 05$ & $8.561 .000,0$ & $57.926 .000,0$ & 576,63 & $56.001 .000,0$ & $114.971 .000,0$ & 105,30 \\
\hline Copasa & 08/02/06 & $288.622 .000,0$ & $364.079 .000,0$ & 26,14 & $365.924 .000,0$ & $511.455 .000,0$ & 39,77 \\
\hline Vivax & 08/02/06 & $38.755 .000,0$ & $77.526 .000,0$ & 100,04 & $44.496 .000,0$ & $-25.966 .000,0$ & $-158,36$ \\
\hline Gafisa & $17 / 02 / 06$ & $27.442 .000,0$ & $48.282 .000,0$ & 75,94 & $66.726 .000,0$ & $128.929 .000,0$ & 93,22 \\
\hline Company & $02 / 03 / 06$ & $10.431 .000,0$ & $63.477 .000,0$ & 508,54 & $23.454 .000,0$ & $106.596 .000,0$ & 354,49 \\
\hline Totvs & 09/03/06 & $15.325 .000,0$ & $29.310 .000,0$ & 91,26 & $82.479 .000,0$ & $205.915 .000,0$ & 149,66 \\
\hline Equatorial & 03/04/06 & $228.844 .000,0$ & $147.063 .000,0$ & $-35,74$ & $138.697 .000,0$ & $316.020 .000,0$ & 127,85 \\
\hline Abnote & $27 / 04 / 06$ & $54.696 .000,0$ & $66.816 .000,0$ & 22,16 & $75.017 .000,0$ & $119.023 .000,0$ & 58,66 \\
\hline CSU CardSystem & $02 / 05 / 06$ & $16.055 .000,0$ & $-25.218 .000,0$ & $-257,07$ & $29.474 .000,0$ & $-9.693 .000,0$ & $-132,89$ \\
\hline Lupatech & $15 / 05 / 06$ & $32.037 .000,0$ & $14.161 .000,0$ & $-55,80$ & $45.042 .000,0$ & $51.334 .000,0$ & 13,97 \\
\hline GP Invest & $01 / 06 / 06$ & $28.289 .044,0$ & $43.754 .586,0$ & 54,67 & $31.178 .264,0$ & $8.277 .000,0$ & $-73,45$ \\
\hline Datasul & 02/06/06 & $20.113 .000,0$ & $24.217 .000,0$ & 20,40 & $60.572 .000,0$ & $70.897 .000,0$ & 17,05 \\
\hline Média & & & & 293,33 & & & 61,20 \\
\hline Mediana & & & & 91,26 & & & 52,67 \\
\hline
\end{tabular}

consideradas as empresas que apresentaram Lucro Líquido ou EBIT negativos (para P/L passado ou P/L futuro) 


\section{Metodologia}

\subsection{Universo e amostra}

$\mathrm{O}$ universo da pesquisa envolve 25 empresas que realizaram oferta pública inicial de ações, no Brasil, entre 26/05/2004 e 02/06/2006.

A utilização de dados "ex-post" na análise, tanto na determinação do custo de capital próprio quanto na análise de múltiplos, restringiu o tamanho da amostra, não possibilitando a análise de empresas que realizaram IPO após 02/06/2006.

As empresas que realizaram emissões iniciais entre maio de 2004 e junho de 2006 foram obtidas através das estatísticas de abertura de capital da Bovespa. ${ }^{6}$ A Tabela 3 abaixo mostra a lista completa de empresas, assim como o ano, o segmento de listagem, o volume negociado, o número de investidores e o número de corretoras participantes em cada emissão.

Tabela 3

Aberturas de capital (05/2004 - 06/2006)

\begin{tabular}{|c|c|c|c|c|c|c|}
\hline \multicolumn{7}{|c|}{ Estatísticas das aberturas de capital na BOVESPA } \\
\hline Ano & Empresa & $\begin{array}{l}\text { Segmento } \\
\text { de listagem }\end{array}$ & $\begin{array}{c}\text { Natureza da } \\
\text { oferta }\end{array}$ & $\begin{array}{c}\text { Volume } \\
\mathrm{R} \$ \text { milhões }\end{array}$ & $\begin{array}{c}\mathrm{N}^{0} \text { de corretoras } \\
\text { varejo }\end{array}$ & $\begin{array}{c}\mathrm{N}^{\mathrm{o}} \mathrm{de} \\
\text { investidores }\end{array}$ \\
\hline \multirow{14}{*}{2006} & Datasul & Novo Mercado & Mista & 317 & 52 & 5.514 \\
\hline & GP Invest & BDR & Primária & 706 & 49 & 2.373 \\
\hline & Lupatech & Novo Mercado & Mista & 453 & 55 & 11.453 \\
\hline & BrasilAgro & Novo Mercado & Primária & 583 & 35 & 3 \\
\hline & CSU CardSyst & Novo Mercado & Mista & 341 & 57 & 14.637 \\
\hline & ABnote & Novo Mercado & Secundária & 480 & 55 & 15.453 \\
\hline & Equatorial & Nível 2 & Mista & 540 & 56 & 7.521 \\
\hline & Totvs & Novo Mercado & Mista & 460 & 57 & 16.322 \\
\hline & Company & Novo Mercado & Mista & 282 & 55 & 13.166 \\
\hline & Gafisa & Novo Mercado & Mista & 927 & 57 & 14.028 \\
\hline & Copasa & Novo Mercado & Primária & 813 & 60 & 15.802 \\
\hline & Vivax & Nível 2 & Mista & 529 & 50 & 7.916 \\
\hline & UOL & Nível 2 & Mista & 625 & 56 & 13.234 \\
\hline & Cosan & Novo Mercado & Primária & 886 & 52 & 9.079 \\
\hline \multirow{6}{*}{2005} & Nossa Caixa & Novo Mercado & Secundária & 954 & 54 & 7.666 \\
\hline & OHL Brasil & Novo Mercado & Mista & 496 & 42 & 1.084 \\
\hline & Energias BR & Novo Mercado & Mista & 1.185 & 44 & 468 \\
\hline & TAM S/A & Nível 2 & Mista & 548 & 48 & 1.212 \\
\hline & Localiza & Novo Mercado & Secundária & 265 & 48 & 809 \\
\hline & Submarino & Novo Mercado & Mista & 473 & 52 & 4.022 \\
\hline \multirow{8}{*}{2004} & Renar & Novo Mercado & Primária & 16 & 42 & 1.698 \\
\hline & Porto Seguro & Novo Mercado & Mista & 377 & 51 & 5.919 \\
\hline & DASA & Novo Mercado & Mista & 437 & 44 & 2.892 \\
\hline & Grendene & Novo Mercado & Secundária & 617 & 56 & 7.905 \\
\hline & CPFL Energia & Novo Mercado & Mista & 821 & 47 & 2.750 \\
\hline & ALL Amer Lat & Nível 2 & Mista & 588 & 33 & 3.425 \\
\hline & Gol & Nível 2 & Mista & 878 & 40 & 11.397 \\
\hline & Natura & Novo Mercado & Secundária & 768 & 32 & 4.445 \\
\hline
\end{tabular}

${ }^{6}$ Para maiores informações acessar www.bovespa.com.br/Principal.asp 
No entanto, três empresas foram retiradas da análise: TAM, Nossa Caixa e Brasil Agro. A primeira já possuía ações listadas na bolsa, apesar de pouco negociadas. A segunda empresa pertence ao setor financeiro e por isso disponibiliza demonstrativos financeiros de maneira distinta das demais companhias. A terceira firma, por sua vez, apresentou reduzido número de negócios após a emissão inicial, dificultando uma análise comparativa de retornos com outras empresas.

A coleta de dados abrangeu o período de janeiro de 2006 a julho de 2007, efetuada pelos próprios autores deste trabalho, por meio de pesquisa bibliográfica em livros, artigos e jornais especializados em finanças, além da busca na internet, nos sites e nos programas Economática e Sabe Invest.

Quanto à pesquisa exploratória, pode-se dividir o trabalho em duas etapas: análise de múltiplos e determinação do custo de capital próprio. Na análise de múltiplos foram utilizados dados dos programas Economática e Sabe Invest, e dos sites da CVM, Bovespa e Infomoney.

Para a determinação do custo de capital do acionista, utilizou-se o Modelo Goldman (CAPM). Para tal, foram utilizados dados obtidos no Economática e nos sites www.portalbrasil.net e www.damodaran.com.

\subsection{Tratamento dos dados}

\section{Determinação do custo de capital próprio (retorno esperado)}

Com o objetivo de calcular o custo de capital próprio ou do acionista, foi utilizado o Modelo Goldman (Harvey, 2001), derivado do modelo CAPM. Suas variáveis foram obtidas através do programa Economática e dos sites www.portalbrasil.net e www.damodaran.com.

Considerando abrangência e metodologia, foram utilizados neste trabalho o S\&P 500, como índice representante do mercado americano, e o IBRX100, para o mercado brasileiro.

Quanto à taxa livre de risco, é recomendada a utilização de títulos do governo americano de longo prazo (t-bonds) para que haja coerência com o tempo de maturação do investimento analisado. (Brigham et alii, 2001).

Para o cálculo das variáveis (taxa livre de risco e retorno de mercado) foi utilizada a média geométrica de 1996 a 2006. O período é adequado, pois, ao mesmo tempo em que reflete características de um mercado mundial mais recente, foi marcado por momentos de crise e expansão econômica, sendo apropriado para analisar investimentos de médio e longo prazo.

O risco-país foi retirado diretamente do site www.portalbrasil.net (Risco Brasil do último dia de cada mês). Utilizou-se o risco país relativo ao mês imediatamente anterior à abertura de capital.

Os betas desalavancados das empresas americanas do setor comparável foram retirados do site www.damodaran.com. Foram utilizados os betas de dezembro do ano anterior ao IPO.

Para alavancar os betas pela estrutura de capital das empresas, utilizou-se a seguinte equação: 


$$
\beta l=\beta u \times\left(1+(1-t) \times\left(\frac{D}{E}\right)\right)
$$

em que,

$\beta l=$ beta alavancado ou do capital próprio (Beta sem leverage);

$\beta u=$ beta desalavancado ou dos ativos (Beta unleveraged);

$(1-t)=1-$ alíquota de impostos;

$D=$ montante de capital de terceiros ou dívidas

$E=$ montante de capital próprio da empresa.

Este artigo utilizou como alíquota de imposto de renda 34\%, prática adotada pelo Economática e coerente com o cenário brasileiro.

Os betas futuros, utilizados na comparação com betas calculados antes da IPO, foram os betas de 12 meses. Estes são os betas das empresas da amostra em relação ao S\&P 500, retirados diretamente do Economática, calculados através das cotações semanais.

Por definição, a estrutura de capital é obtida pela razão entre a dívida líquida e o valor de mercado do patrimônio líquido. Ambos os dados foram obtidos do Economática.

Devido à dificuldade em obter projeções no momento da IPO, referentes à estrutura de capital que a empresa adotará, foram usados dados futuros como aproximação. Para tal, foi utilizado o demonstrativo seguinte aos 12 meses posteriores ao IPO. Ou seja, se a empresa realizou IPO em maio de 2004, utilizou-se a estrutura de capital que ela possuía em junho de 2005. A utilização deste critério pode causar um viés nos resultados, já que não necessariamente a estrutura de capital futura corresponde a estrutura de capital planejada no momento da IPO.

Por fim, foram calculadas as estruturas de capital imediatamente após a IPO, visando verificar se existia diferença relevante em relação à estrutura 12 meses após à emissão. Para tal, foram utilizados dados do trimestre posterior à emissão. Notou-se que não existia diferença significativa, ratificando o fato de que as empresas em sua maioria possuiam pouco endividamento na IPO. Este indicador é condizente com o fato de que a expressiva captação de recursos reduziu a dívida líquida das empresas. Soma-se a isto a elevada valorização das ações após a abertura de capital, reduzindo a relação entre dívida e valor de mercado.

\section{Cálculos efetuados com retornos esperados (modelo Goldman) e betas}

Após a obtenção dos dados, foram comparados os retornos mensurados através do modelo e os retornos que ocorreram no período de 12 meses após a IPO.

Além disso, foram comparados os betas utilizados no modelo e os betas calculados após a IPO.

Para ambas as comparações testou-se a igualdade através de testes $t$ para amostras pequenas dependentes (McClave et alii, 2000). 


\section{Análise de múltiplos}

O trabalho utilizou dois múltiplos como referência: Preço/Lucro e Enterprise Value/EBIT. A escolha se deve a importância e popularidade dos índices entre pesquisadores, investidores e analistas, discutidas no referencial teórico.

As variáveis que compõem os múltiplos foram obtidas através dos programas Economática e SabeInvest, e dos sites da CVM, da Bovespa e Infomoney.

Utilizou-se o conceito de "múltiplo futuro", definido pela razão entre o preço corrente e projeções do lucro ou do EBIT. O múltiplo futuro é recomendado por diversos autores, entre os quais Liu et alii (2002). O fato de as empresas que realizaram IPO, entre 2004 e 2006 no Brasil, terem apresentado crescimento significativo nos anos posteriores à emissão, inibe a utilização de múltiplos passados ou correntes ${ }^{7}$.

Foram utilizados Lucro e EBIT futuros (balanço seguinte aos 12 meses posteriores à emissão) como uma aproximação para lucro e EBIT projetados no momento da IPO. Ou seja, se a empresa realizou IPO em maio de 2004, utilizou-se o lucro ou EBIT (contemplando 12 meses) de junho de 2005. Novamente, ressalta-se que a utilização de dados futuros como aproximação para dados projetados pode gerar distorções nos resultados, já que as empresas podem ter projetado resultados divergentes dos obtidos.

Os retornos após a emissão inicial (retornos de 1 dia, 1 mês, 2 meses, 6 meses e 12 meses) foram obtidos, exclusivamente, a partir de cotações do Economática. Foram utilizadas cotações de fechamento ajustadas para proventos e dividendos.

Os retornos para a ação i foram obtidos através da equação:

$$
i, t R=\left(\frac{i, t P}{i, \text { ofertaP }}-1\right) \times 100
$$

onde:

$R_{i, t}=$ Retorno da ação i no período $\mathrm{t}$

$P_{i, t}=$ Cotação de fechamento da ação $i$ no período $t$

$P_{i, o f e r t a}=$ Cotação de fechamento da ação $i$ um dia antes da oferta. ${ }^{8}$

A cotação de fechamento um dia antes do início das negociações corresponde à cotação estabelecida para a oferta inicial.

Como meio de evitar possíveis distorções nos retornos, adotou-se também o retorno ajustado pelo retorno de mercado.

Como índice de mercado utilizou-se o IBRX100, devido a sua ampla abrangência e metodologia de cálculo.

Os retornos do mercado para o mesmo período foram obtidos através da equação:

\footnotetext{
${ }^{7}$ Ver tabela 2

${ }^{8}$ No sistema Economática, a cotação de determinada ação na oferta inicial é obtida através da cotação de fechamento do dia anterior à oferta.
} 


$$
m, t R=\left(\frac{m, t P}{m, o f e r t a P}-1\right) \times 100
$$

onde:

$R m, t=$ Retorno do mercado no período $t$

$P m, t=$ Cotação de fechamento do mercado no período $t$

Pm,oferta = Cotação de fechamento do mercado um dia antes da oferta

Para o cálculo dos retornos ajustados foram utilizadas cinco abordagens distintas presentes na literatura: AR, MAAR, MMAR e BHAR.

- Market Adjusted Return (AR)

$$
A R=i, t R-m, t R
$$

onde:

$R i, t=$ retorno da ação i até o período $t$;

$R_{m, t}=$ retorno do índice de mercado até o período $t$.

Além da versão acima citada, utilizou-se uma versão derivada do AR, considerando-se o risco sistemático de cada ativo.

$$
A R=i, t R-m, t \beta . R
$$

onde:

$R i, t=$ retorno da ação i até o período $t$;

$\beta=$ Beta (Risco Sistêmico);

$R_{m, t}=$ retorno do índice de mercado até o período $t$.

- Market Adjusted Abnormal Return (MAAR)

Utilizando o mesmo procedimento que Aggarwal et alii (1993), calculou-se o MAAR (Market Adjusted Abnormal Return).

$$
M A A R_{i, t}=\left(\left(\frac{i, t 1+R}{m, t 1+R}\right)-1\right) \times 100
$$

onde:

$R_{i, t}=$ retorno da ação i até o período $t$;

$R_{m, t}=$ retorno do índice de mercado até o período $t$.

- Average Monthly Market-Adjusted Return (MMAR)

De acordo com Chi e Padgett (2005), apud Procianoy e Cigerza (2007):

$$
M M A R_{i, t}=\frac{\left(\left(\frac{i, t 1+R}{m, t 1+R}\right)-1\right)}{n} \times 100
$$


onde:

$R_{i, t}=$ retorno da ação i até o período $t$;

$R_{m, t}=$ retorno do índice de mercado até o período $t$

$n=$ numero de meses até o período $t$.

- Buy and Hold Adjusted Return (BHAR)

Ritter e Welch (2002), Gunther e Rummer (2006), Chi e Padgett (2005), Ljungqvist (2004), apud Procianoy e Cigerza (2007), usam BHAR para calcular retornos de longo prazo. Este procedimento difere-se dos demais por não considerar os ganhos do primeiro dia, sendo calculado segundo a equação:

$$
i, t B H A R=\left(\frac{\frac{i, t P}{i, 1 P}}{\frac{m, t P}{m, 1 P}}\right)-1
$$

onde:

$P_{i, t}=$ preço da ação $i$ no fechamento do dia $t$;

$P_{i, 1}=$ preço da ação $i$ no fechamento do primeiro dia;

$P_{m, t}=$ preço do índice de mercado no fechamento do dia $t ;$

$P_{m, 1}=$ preço do índice de mercado no fechamento do primeiro dia.

\section{Empresas comparáveis}

Para a obtenção dos múltiplos de empresas comparáveis utilizou-se um procedimento de ajuste. Primeiramente, foram calculadas as medianas dos setores americanos aos quais pertencem as empresas da amostra. A mediana, neste caso, serve como uma medida de posição mais conservadora do que a média, amenizando a influência de eventuais outliers. A utilização da mediana como mediada de posição também foi realizada por Alford (1992) e O'Hanlon et alii (2007). No entanto, Baker e Ruback (1999) e Liu et alii (2002) consideram mais eficaz a utilização da média harmônica. No caso deste estudo, entretanto, por serem analisados setores que possuiam poucas empresas, poderiam ser gerados múltiplos não representativos para a amostra, caso a média harmônica fosse utilizada. Ressalta-se que no trabalho de Baker e Ruback (1999) foram apenas considerados setores com mais de sete empresas, o que não acontece neste estudo.

Em seguida, as medianas calculadas foram ajustadas para o cenário brasileiro, através de uma taxa de desconto (múltiplo da bolsa brasileira no período/ múltiplo da bolsa americana no período).

Damodaran (1999) cita a dificulade em analisar empresas que possuem escasso grupo de concorrentes. Tal situação foi determinante neste estudo. Em alguns setores, "de cosmético" por exemplo, não existiam empresas nacionais comparáveis no momento da IPO.

De acordo com Famá e Santiago Filho (2001), quando não existem empresas de um determinado setor negociadas em bolsa de valores, avalia-se determinada oportunidade de investimento apenas através dos múltiplos de empresas estrangeiras comparáveis. No entanto, estas práticas podem induzir a erros, pois não 
são levadas em consideração variáveis que podem afetar o desempenho do mercado financeiro de determinado país. Estas variáveis, dependendo do tipo de setor analisado, podem levar em consideração aspectos políticos, econômicos, de nível educacional da população, volume médio de negociação em bolsas de valores e risco-país. Dittmann e Weiner (2005) expõem esta questão e verificam que para alguns casos não devem ser utilizadas empresas comparáveis com sede em outro país.

Outro critério utilizado foi a escolha aleatória de empresas americanas dentro de determinado setor (Alford, 1992). Mesmo utilizando o abrangente universo de empresas americanas, em alguns casos observou-se escassez de empresas comparáveis (exemplo: setor de locação de veículos). Logo, a utilização de outros métodos de busca de empresas similares (Bhojraj e Lee, 2002) foram descartados.

Desta forma, caso esteja sendo analisada a IPO de uma empresa brasileira do setor de transporte aéreo, ocorrida em junho de 2004, calcular-se-á a mediana dos múltiplos do setor americano de transporte aéreo do trimestre anterior (março de 2004). Se a mediana do setor americano era 10, em 31/03/2004, e a taxa de desconto para o período era de 0,60 (explicada mais adiante), adotou-se como aproximação para o múltiplo do setor brasileiro de transporte aéreo $6(10 \times 0,6)$.

Para alocar as empresas em setores, utilizou-se a classificação NAICS (North American Industry Classification System), disponível no Economática. Para tal, julgou-se apropriado o "Nível "2", que classifica as empresas em 96 categorias distintas.

\section{Obtenção de taxa de desconto entre múltiplos dos mercados brasileiro e amer- icano}

Foram coletados múltiplos de empresas que são listadas na Bovespa, para o caso brasileiro, e NYSE, AMEX e NASDAQ, para o caso americano. Foram utilizados múltiplos de dezembro de 2003, 2004, 2005 e 2006, ponderados pelos volumes financeiros negociados em cada ano, para cada ação.

Primeiramente, foram retirados os valores menores ou iguais a zero, incoerentes com o conceito de múltiplo. Os números maiores que o terceiro quartil foram igualados a tal valor, inibindo eventuais outliers. Finalmente, foram calculadas as médias ponderadas pelo volume financeiro negociado durante o ano em questão. ${ }^{9}$ As taxas de desconto e dados relevantes são apresentados abaixo.

\footnotetext{
${ }^{9}$ Além da média, foram calculadas as medianas.
} 
Tabela 4

Taxa de desconto entre múltiplos brasileiros e americanos

\begin{tabular}{|c|c|c|c|c|c|c|c|c|}
\hline \multicolumn{9}{|c|}{ Bovespa } \\
\hline & \multicolumn{4}{|c|}{$\mathrm{P} / \mathrm{L}$} & \multicolumn{4}{|c|}{ EV/EBIT } \\
\hline Ano & dez.03 & dez.04 & dez.05 & dez.06 & dez.03 & dez.04 & dez.05 & dez.06 \\
\hline Número de empresas & & & & & & & & \\
\hline Volume empresas/ & 318 & 343 & 302 & 334 & 315 & 344 & 297 & 299 \\
\hline Volume bolsa (\%) & 92,21 & 31,95 & 93,61 & 94,39 & 90,60 & 91,48 & 86,51 & 86,33 \\
\hline Média ponderada & 10,23 & 10,29 & 9,84 & 14,03 & 7,80 & 6,64 & 6,92 & 9,13 \\
\hline \multicolumn{9}{|c|}{ Nyse, Nasdaq e Amex } \\
\hline & \multicolumn{4}{|c|}{$\mathrm{P} / \mathrm{L}$} & \multicolumn{4}{|c|}{ EV/EBIT } \\
\hline Ano & dez.03 & dez.04 & dez.05 & dez.06 & dez.03 & dez.04 & dez.05 & dez.06 \\
\hline Número de empresas & & & & & & & & \\
\hline Volume empresas/ & 1114 & 1176 & 1145 & 1106 & 987 & 1035 & 1019 & 985 \\
\hline Volume bolsa (\%) & 86,53 & 91,15 & 91,68 & 92,77 & 76,33 & 80,40 & 81,56 & 83,71 \\
\hline Média ponderada & 18,89 & 18,55 & 17,16 & 16,49 & 13,84 & 13,45 & 12,56 & 12,11 \\
\hline Taxa de desconto & 0,541 & 0,555 & 0,574 & 0,851 & 0,564 & 0,493 & 0,551 & 0,754 \\
\hline
\end{tabular}

Nota-se que as taxas de desconto são calculadas apenas para o mês de dezembro de cada ano (No Economática, a base de dados para o restante dos meses apresenta muitos missing values. ${ }^{10}$ ) Buscando um meio de comparação mais eficiente, foram calculadas taxas de desconto para o mês de junho de cada ano, através da média entre o mês de dezembro do ano anterior e o mês de dezembro do ano posterior.

Tabela 5

Taxas de desconto ajustadas entre mercado brasileiro e americano

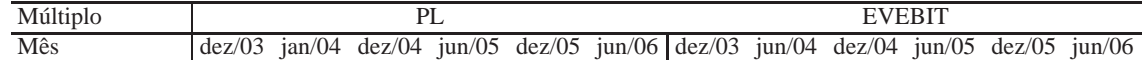
\begin{tabular}{l|llllll|lllllll}
\hline Taxa de desconto & 0,5414 & 0,5481 & 0,5547 & 0,5642 & 0,5736 & 0,7123 & 0,5638 & 0,5286 & 0,4934 & 0,5222 & 0,5511 & 0,6525 \\
\hline
\end{tabular}

Ao observar-se a tabela, verifica-se o expressivo crescimento dos múltiplos do mercado brasileiro. Ao compará-los com os múltiplos americanos, nota-se que a diferença entre os índices diminuiu significativamente nos últimos anos.

\footnotetext{
${ }^{10}$ Valores ausentes. 


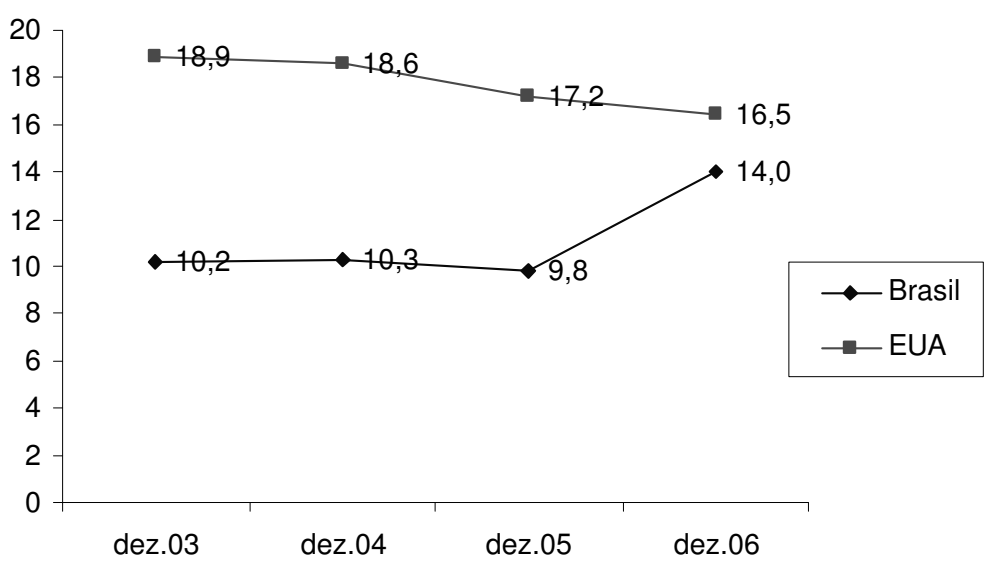

Figura 3

P/L Brasil x P/L EUA

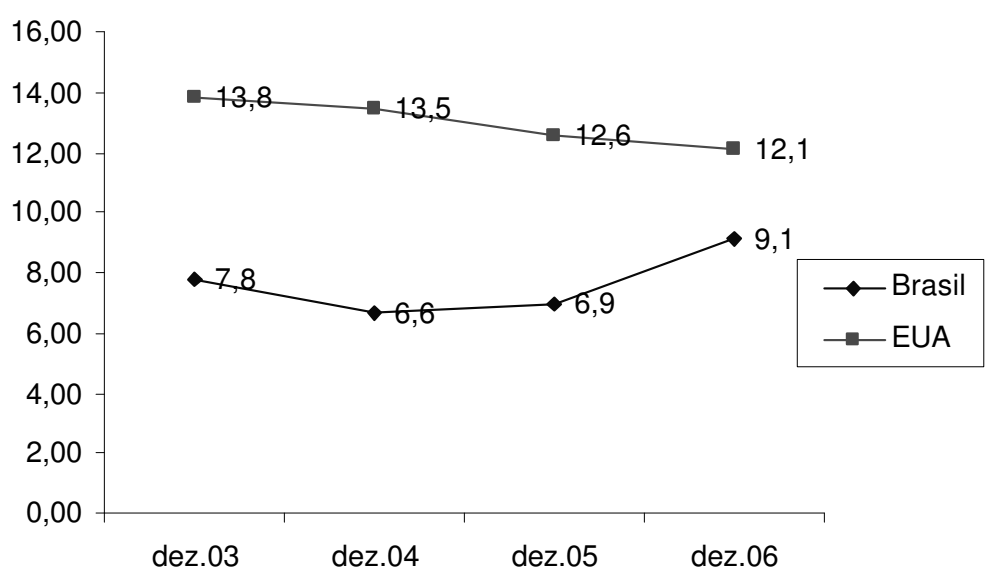

Figura 4

EV/EBIT Brasil x EV/EBIT EUA 


\section{Cálculos efetuados com múltiplos obtidos}

A taxa de desconto encontrada foi aplicada à mediana do setor americano, como forma de encontrar um resultado plausível que pudesse expressar o múltiplo do setor brasileiro.

Verificou-se então a diferença entre médias e medianas através de testes estatísticos (Teste $t$ para amostras pequenas independentes e Teste dos Sinais). Este trabalho utilizou três testes estatísticos, sugeridos por McClave et alii (2000), para verificar as diferenças entre médias e medianas das amostras. Para os dois primeiros testes a principal premissa assumida é a de que as populações devem possuir distribuição normal. Para verificar a normalidade dos dados foi utilizado o programa SPSS ${ }^{11}$ (Teste de Shapiro-Wilk).

\section{Análise dos Resultados}

\subsection{Retornos anormais}

Os elevados retornos iniciais nos processos de IPO foram verificados por diversos autores, no Brasil e no mundo. Como esperado, no presente estudo foram também verificados elevados retornos anormais de curto prazo, e baixos retornos anormais de longo prazo.

Ao analisar a amostra, verificou-se que a média dos retornos do primeiro dia foi de $8,3 \%$ e a mediana $6,3 \%$.

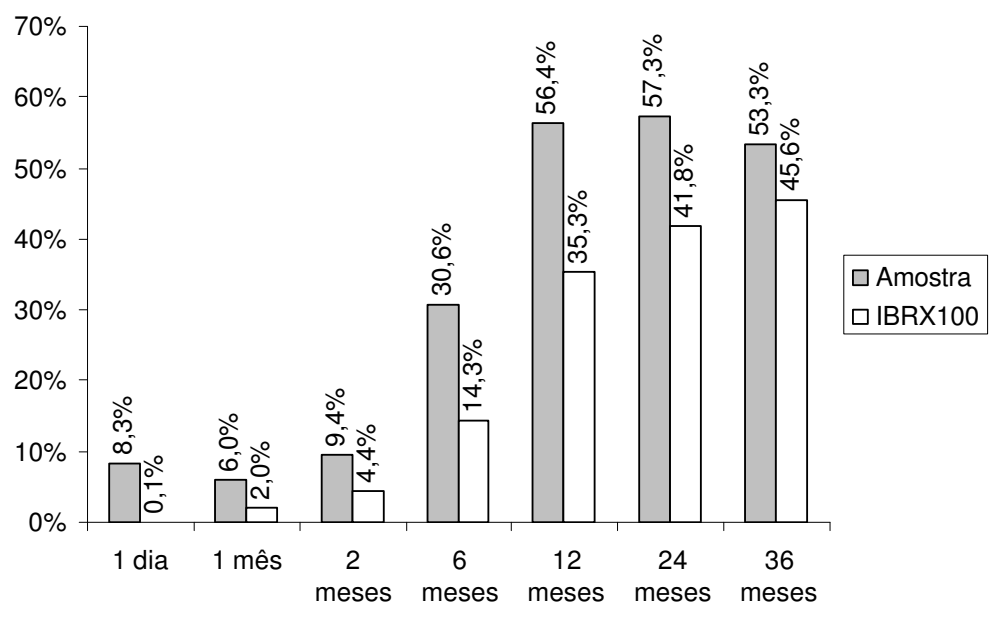

Figura 5

Retorno total amostra x retorno total IBRX100

\footnotetext{
${ }^{11}$ Statistical Package for the Social Sciences. Para maiores informações acessar: www.spss.com 
Utilizando o MAAR como medida de ajuste, a média dos retornos anormais iniciais da amostra foi $8,27 \%$ e a mediana $8,93 \%$.

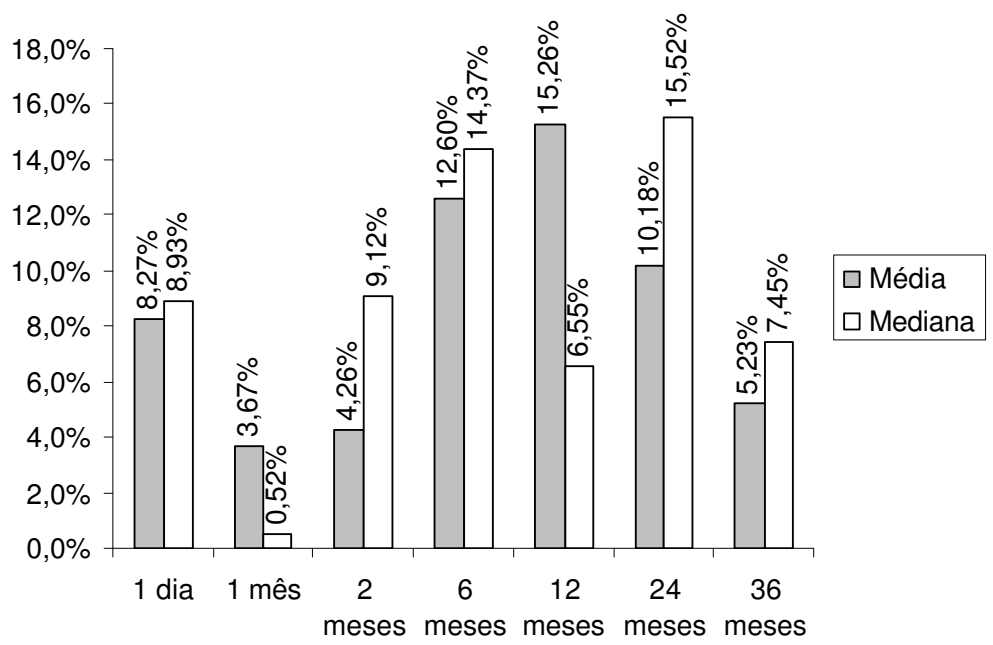

Figura 6

MAAR (market-adjusted abnormal returns)

Para analisar os retornos de longo prazo (incluído o período de 6 meses) foram utilizados os seguuintes métodos: AR, MMAR (considera o primeiro dia) e BHAR (não considera o primeiro dia), como medidas de ajuste.

Ao utilizar o AR (Anexo 9), observou-se que quando ajustados pelo risco sistêmico os retornos são significativamente menores do que quando não ajustados. Não foi considerado o período de 6 meses devido ao pequeno número de observações para a variável beta.

Ao usar MMAR foram encontrados retornos anormais mensais muito baixos para 12 meses $(1,27 \%), 24$ meses $(0,42 \%)$ e 36 meses $(0,15 \%)$. Quando o BHAR (método mais comum na análise de longo prazo) é utilizado, os retornos de 12 meses, 24 meses e 36 meses, são respectivamente $6,55 \%, 3,54 \%$ e $-0,46 \%$. Ao ajustar o BHAR para retornos mensais (dividindo os retornos encontrados pelo número de meses) os resultados são $0,55 \%, 0,15 \%$ e $-0,01 \%$. 


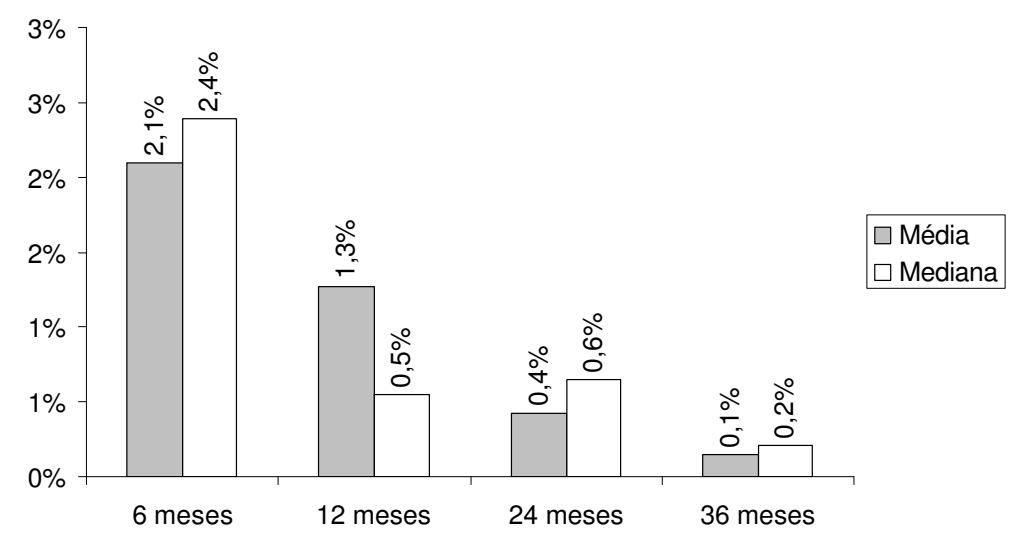

Figura 7

MMAR (monthly market-adjusted returns)

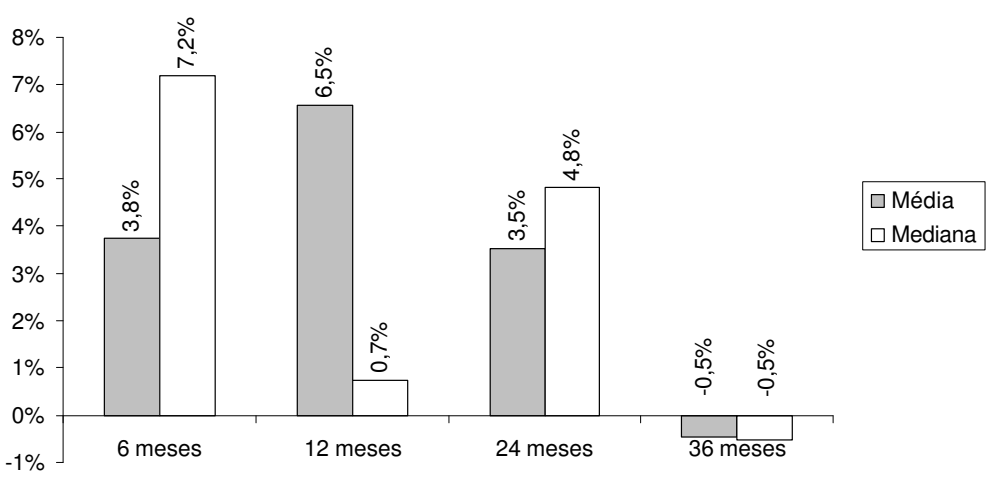

Figura 8

BHAR (buy-and-hold abnormal returns)

\subsection{Análise dos múltiplos}

$\mathrm{Na}$ análise dos múltiplos (P/L e EV/EBIT), verificou-se que as empresas da amostra não utilizaram (na média) múltiplos com deságio, quando comparadas com empresas similares. Estes resultados são mostrados nas Tabelas 6 e 7 abaixo, nas células que mostram as médias e medianas da relação Múltiplo da Empresa / Múltiplo do Setor Brasileiro. A coluna "Setor Brasileiro" refere-se ao setor americano ajustado pela Taxa de Desconto (ou ajuste) entre os mercados brasileiro e americano. 
Ao comparar-se os múltiplos das empresas no momento da IPO aos múltiplos dos setores (calculados no trimestre anterior), observou-se que a média e mediana dos múltiplos adotados pelas empresas são maiores que as dos múltiplos do setor ao qual pertencem.

No caso dos P/Ls passados (lucros passados), quando eliminados os valores negativos, somente a empresa Localiza apresentou $\mathrm{P} / \mathrm{L}$ inferior ao $\mathrm{P} / \mathrm{L}$ do setor brasileiro correspondente.

No caso de P/Ls projetados (lucro futuro), 9 empresas (Natura, CPFL, Porto Seguro, Localiza, Energias BR, OHL Brasil, Cosan, Copasa e GP) das 25 analisadas apresentaram índices $\mathrm{P} / \mathrm{L}$ inferiores ao do setor brasileiro.

$\mathrm{Na}$ análise dos múltiplos EV/EBIT, 3 empresas (Porto Seguro, Localiza e Datasul) apresentaram números menores do que os dos Setores Brasileiros correspondentes, no caso de valores passados.

Para o múltiplo EV/EBIT projetado (EBIT futuro), 10 empresas (Natura, Gol, Localiza, Energias BR, OHL Brasil, Copasa, Totvs, Equatorial, American Banknote e Datasul) apresentaram valores menores do que os dos setores brasileiros correspondentes.

As tabelas abaixo demonstram as diferenças nos cálculos de múltiplos passados e múltiplos futuros. Devido ao período de crescimento experimentado pelas empresas da amostra, no período próximo à emissão, os múltiplos passados apresentam números elevados, podendo, se utilizados, gerar distorções na análise comparativa.

No entanto, ao realizar-se testes estatísticos para verificar diferença entre médias e medianas (McClave et alii, 2000), não se observou significância.

Para verificar a hipótese de que a média da amostra é maior do que a média do setor foi utilizado o teste $t$ para amostras pequenas e independentes. Ao nível de significância de 5\%, conclui-se que não há evidências de que a média da amostra seja maior do que a média do setor. No entanto, ressalta-se que ao observar o teste de Shapiro-Wilk, uma das premissas não é satisfeita: a normalidade dos dados (Tabela 8). 
Tabela 6

Comparação dos índices P/L

\begin{tabular}{|c|c|c|c|c|c|c|}
\hline \multirow[b]{2}{*}{ Empresas } & \multirow[b]{2}{*}{ Data do IPO } & \multicolumn{4}{|c|}{$\mathrm{P} / \mathrm{L}$} & \multirow{2}{*}{$\begin{array}{c}\text { Múltiplo Empresa } / \\
\text { Múltiplo Setor } \\
\text { Brasileiro }\end{array}$} \\
\hline & & \begin{tabular}{|l|} 
Passado \\
\end{tabular} & Futuro & $\begin{array}{c}\text { Setor } \\
\text { Americano }\end{array}$ & $\begin{array}{c}\text { Setor } \\
\text { Brasileiro }\end{array}$ & \\
\hline Natura & $26 / 05 / 04$ & 48,84 & 9,33 & 28,30 & 15,51 & 0,60 \\
\hline Gol & $24 / 06 / 04$ & 44,08 & 13,97 & 20,90 & 11,45 & 1,22 \\
\hline ALL America Latina & $25 / 06 / 04$ & 193,18 & 13,20 & 16,30 & 8,93 & 1,48 \\
\hline CPFL Energia & $29 / 09 / 04$ & $-26,14$ & 7,61 & 15,10 & 8,28 & 0,92 \\
\hline Grendene & $29 / 10 / 04$ & 15,25 & 36,30 & 15,60 & 8,65 & 4,19 \\
\hline Dasa & 19/11/04 & $-124,46$ & 103,94 & 17,30 & 9,60 & 10,83 \\
\hline Porto Seguro & $22 / 11 / 04$ & 9,87 & 5,60 & 12,65 & 7,02 & 0,80 \\
\hline Renar Macas & $28 / 02 / 05$ & 62,38 & $-14,72$ & 19,00 & 10,54 & $-1,40$ \\
\hline Submarino & $30 / 03 / 05$ & 134,28 & 45,92 & 31,90 & 17,70 & 2,60 \\
\hline Localiza & $23 / 05 / 05$ & 7,02 & 7,79 & 20,30 & 11,45 & 0,68 \\
\hline Energias BR & $13 / 07 / 05$ & 16,67 & 4,52 & 17,50 & 9,87 & 0,46 \\
\hline OHL Brasil & $15 / 07 / 05$ & 49,13 & 11,86 & 31,50 & 17,77 & 0,67 \\
\hline Cosan & $18 / 11 / 05$ & 175,68 & 8,41 & 18,95 & 10,87 & 0,77 \\
\hline Universo Online & $16 / 12 / 05$ & $-15,17$ & 31,75 & 24,10 & 13,82 & 2,30 \\
\hline Copasa MG & 08/02/06 & 9,06 & 7,19 & 15,80 & 9,06 & 0,79 \\
\hline Vivax & 08/02/06 & 69,79 & 34,89 & 22,50 & 12,91 & 2,70 \\
\hline Gafisa & $17 / 02 / 06$ & 74,14 & 42,14 & 7,40 & 4,24 & 9,93 \\
\hline Company & 02/03/06 & 55,22 & 9,07 & 7,40 & 4,24 & 2,14 \\
\hline Totvs & 09/03/06 & 55,73 & 29,14 & 25,35 & 14,54 & 2,00 \\
\hline Equatorial & 03/04/06 & 12,46 & 19,39 & 15,90 & 11,33 & 1,71 \\
\hline American Banknote & $27 / 04 / 06$ & 15,54 & 12,72 & 17,60 & 12,54 & 1,01 \\
\hline CSU CardSystem & $02 / 05 / 06$ & 54,46 & $-34,67$ & 24,50 & 17,45 & $-1,99$ \\
\hline Lupatech & $15 / 05 / 06$ & 26,49 & 59,93 & 17,90 & 12,75 & 4,70 \\
\hline GP Investments & $01 / 06 / 06$ & 35,94 & 23,23 & 42,65 & 30,38 & 0,76 \\
\hline Datasul & $02 / 06 / 06$ & 25,93 & 21,54 & 24,00 & 17,10 & 1,26 \\
\hline Número de observações & & 22 & 23 & 23 & 23 & 23 \\
\hline Média & & 54,14 & 24,32 & 20,30 & 12,17 & 2,37 \\
\hline Mediana & & 46,46 & 13,97 & 17,90 & 11,45 & 1,26 \\
\hline Desvio Padrão & & 51,48 & 22,94 & 8,01 & 5,45 & 2,76 \\
\hline
\end{tabular}


Tabela 7

Comparação dos índices EV/EBIT

\begin{tabular}{|c|c|c|c|c|c|c|}
\hline \multirow[b]{2}{*}{ Empresas } & \multirow[b]{2}{*}{ Data do IPO } & \multicolumn{4}{|c|}{ EV/EBIT } & \multirow{2}{*}{$\begin{array}{c}\text { Múltiplo Empresa / } \\
\text { Múltiplo Setor } \\
\text { Brasileiro }\end{array}$} \\
\hline & & Passado & Futuro & $\begin{array}{c}\text { Setor } \\
\text { Americano }\end{array}$ & $\begin{array}{c}\text { Setor } \\
\text { Brasileiro }\end{array}$ & \\
\hline Natura & $26 / 05 / 04$ & 13,80 & 8,184 & 19,70 & 10,41 & 0,79 \\
\hline Gol & $24 / 06 / 04$ & 22,11 & 9,596 & 19,30 & 10,20 & 0,94 \\
\hline ALL America Latina & $25 / 06 / 04$ & 15,89 & 11,237 & 13,10 & 6,92 & 1,62 \\
\hline CPFL Energia & 29/09/04 & 10,93 & 6,712 & 12,60 & 6,66 & 1,01 \\
\hline Grendene & 29/10/04 & 13,95 & 25,645 & 9,00 & 4,44 & 5,78 \\
\hline Dasa & 19/11/04 & 24,52 & 17,806 & 11,20 & 5,53 & 3,22 \\
\hline Porto Seguro & $22 / 11 / 04$ & 1,77 & 17,706 & 8,20 & 4,05 & 4,38 \\
\hline Renar Macas & $28 / 02 / 05$ & 21,88 & 3087,519 & 13,70 & 6,76 & 456,80 \\
\hline Submarino & $30 / 03 / 05$ & 95,41 & 86,604 & 27,70 & 13,67 & 6,34 \\
\hline Localiza & $23 / 05 / 05$ & 5,49 & 4,492 & 12,80 & 6,68 & 0,67 \\
\hline Energias BR & $13 / 07 / 05$ & 9,88 & 6,070 & 13,80 & 7,21 & 0,84 \\
\hline OHL Brasil & $15 / 07 / 05$ & 12,42 & 8,465 & 18,25 & 9,53 & 0,89 \\
\hline Cosan & $18 / 11 / 05$ & 20,13 & 7,726 & 12,65 & 6,97 & 1,11 \\
\hline Universo Online & $16 / 12 / 05$ & $-213,07$ & 17,380 & 16,10 & 8,87 & 1,96 \\
\hline Copasa MG & 08/02/06 & 9,86 & 7,051 & 13,50 & 7,44 & 0,95 \\
\hline Vivax & $08 / 02 / 06$ & 24,55 & $-42,062$ & 20,05 & 11,05 & $-3,81$ \\
\hline Gafisa & $17 / 02 / 06$ & 39,25 & 20,311 & 5,90 & 3,25 & 6,25 \\
\hline Company & $02 / 03 / 06$ & 31,56 & 6,943 & 5,90 & 3,25 & 2,14 \\
\hline Totvs & 09/03/06 & 10,73 & 4,297 & 18,45 & 10,17 & 0,42 \\
\hline Equatorial & 03/04/06 & 12,01 & 5,270 & 13,40 & 8,74 & 0,60 \\
\hline American Banknote & $27 / 04 / 06$ & 11,86 & 7,472 & 13,10 & 8,55 & 0,87 \\
\hline CSU CardSystem & $02 / 05 / 06$ & 31,06 & $-94,455$ & 13,90 & 9,07 & $-10,41$ \\
\hline Lupatech & $15 / 05 / 06$ & 19,21 & 16,857 & 13,20 & 8,61 & 1,96 \\
\hline GP Investments & $01 / 06 / 06$ & 31,45 & 118,457 & 30,90 & 20,16 & 5,87 \\
\hline Datasul & 02/06/06 & 8,02 & 6,855 & 16,50 & 10,77 & 0,64 \\
\hline Número de observações & & 24 & 22 & 22 & 22 & 22 \\
\hline Média & & 20,74 & 19,14 & 14,78 & 8,28 & 2,24 \\
\hline Mediana & & 14,92 & 8,32 & 13,30 & 7,99 & 1,06 \\
\hline Desvio Padrão & & 18,44 & 28,05 & 6,07 & 3,73 & 2,07 \\
\hline
\end{tabular}

* As linhas rachuradas indicam que não foram utilizados os dados da empresa para o cálculo da média,

mediana e desvio padrão. Múltiplos negativos não são analisados.

** A última coluna utiliza o múltiplo futuro para cálculo.

***A coluna de "Setor Brasileiro" é calculada através do desconto do setor americano, explicado anteriormente. 


\begin{tabular}{lcc}
\hline & \multicolumn{2}{c}{ Shapito-Wilk } \\
& Estatística & Significância \\
\hline PL Amostra & 0,768 & 0,000 \\
PL Setor & 0,858 & 0,005 \\
EV/EBIT amostra & 0,519 & 0,000 \\
EV/EBIT setor & 0,884 & 0,014 \\
\hline
\end{tabular}

Após a violação da premissa do teste, justificou-se necessário verificar outra hipótese: a mediana da amostra é maior do que a mediana do setor. Para tal foi utilizado um teste não paramétrico denominado Teste dos Sinais, mais robusto do que o teste $t$ para amostras pequenas independentes.

Ao nível de significância de 5\%, conclui-se que não existem evidências de que a mediana da amostra é maior do que a mediana do setor.

$\mathrm{O}$ resultado sugere a existência de uma bolha especulativa no momento da emissão inicial, como tratado por Leal (1991) já que os retornos anormais de curto prazo foram elevados mesmo não existindo deságio no preço da ação. Segundo Tiniç (1988), devido à pressão demandante de investidores que não conseguiram comprar todas as ações que desejaram, os retornos iniciais são elevados até que em determinado momento retornos excedentes negativos são observados.

How et alii (2007), ao testarem a relação entre a precificação por múltiplos e os retornos inicias, verificaram que quanto mais sub-avaliadas as empresas, maiores são os retornos iniciais.

\subsection{Análise dos custos de capitais próprios e betas observados após 12 meses}

Buscando avaliar o custo de capital próprio utilizado pelas empresas que abriram capital entre maio de 2004 e junho de 2006, foi utilizado o CAPM, modificado através do modelo Goldman Sachs.

Verificou-se que a média de retornos (em dólar) calculada de acordo com o modelo Goldman Sachs é significativamente mais baixa do que os retornos verificados nos 12 meses após a IPO (em dólar). Mesmo para as empresas que apresentam retornos para 24 e 36 meses (retornos que tenderiam a ser mais estáveis), a diferença foi mantida. 
Tabela 9

Testes estatísticos para múltiplos

\begin{tabular}{|c|c|c|c|c|c|c|c|}
\hline Teste & Descrição & Premissa & $\begin{array}{l}\text { Objeto do } \\
\text { estudo }\end{array}$ & Hipóteses & $\begin{array}{c}\text { Nível de } \\
\text { significância }\end{array}$ & $\begin{array}{c}\text { Estatística de } \\
\text { teste }\end{array}$ & Conclusão \\
\hline 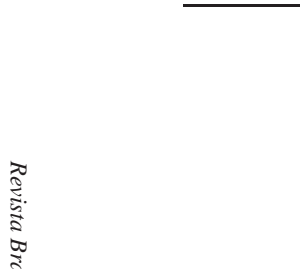 & $\begin{array}{l}\text { Teste } t \text { para médias } \\
\text { de amostras peque- } \\
\text { nas independentes }\end{array}$ & $\begin{array}{l}\text { Populações } \\
\text { suem distribuição } \\
\text { normal }\end{array}$ & $\mathrm{P} / \mathrm{L}$ & $\begin{array}{l}\text { Ho: } \begin{array}{c}\text { Múltiplos } \\
\text { das Empresas = } \\
\text { Múltplos do Setor }\end{array} \\
\text { H1: Múltiplos } \\
\text { das Empresas > } \\
\text { Múltplos do Setor }\end{array}$ & 0,05 & 1,005 & $\begin{array}{l}\text { Não existem } \\
\text { evidências de } \\
\text { que a média da } \\
\text { amostra é maior } \\
\text { do que a média } \\
\text { do setor }\end{array}$ \\
\hline 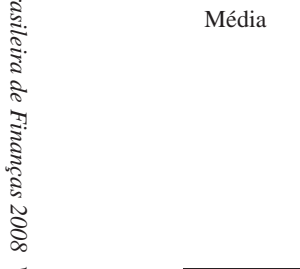 & & & EV/EBIT & $\begin{array}{l}\text { Ho: } \begin{array}{c}\text { Múltiplos } \\
\text { das Empresas = } \\
\text { Múltplos do Setor }\end{array} \\
\text { H1: Múltiplos } \\
\text { das Empresas > } \\
\text { Múltplos do Setor }\end{array}$ & 0,05 & 0,597 & $\begin{array}{l}\text { Não existem } \\
\text { evidências de } \\
\text { que a média da } \\
\text { amostra é maior } \\
\text { do que a média } \\
\text { do setor }\end{array}$ \\
\hline $\begin{array}{l}\frac{1}{2} \\
\frac{a}{2} \\
\vdots\end{array}$ & Teste dos Sinais & $\begin{array}{l}\text { Teste mais robusto } \\
\text { do que o teste } t \text { para } \\
\text { médias }\end{array}$ & $\mathrm{PL}$ & $\begin{array}{l}\text { Ho: Múltiplos das } \\
\text { Empresas = 11,453 } \\
\text { H1: Múltiplos das } \\
\text { Empresas > 11,453 }\end{array}$ & 0,05 & $0,105^{*}$ & $\begin{array}{l}\text { Não existem } \\
\text { evidências de } \\
\text { que a mediana } \\
\text { da amostra é } \\
\text { maior do que a } \\
\text { mediana do setor }\end{array}$ \\
\hline Mediana & & & EV/EBIT & $\begin{array}{l}\text { Ho: Múltiplos das } \\
\text { Empresas }=7,994 \\
\text { H1: Múltiplos das } \\
\text { Empresas }>7,994\end{array}$ & 0,05 & $0,415^{*}$ & $\begin{array}{l}\text { Não existem evi- } \\
\text { dencias de que a } \\
\text { mediana das em- } \\
\text { presas é maior do } \\
\text { que a do setor }\end{array}$ \\
\hline
\end{tabular}


Tabela 10

\begin{tabular}{|c|c|c|c|c|c|c|c|c|}
\hline \multirow[b]{2}{*}{ Empresas } & \multirow[b]{2}{*}{ Data do IPO } & $k e(U S \$)$ & \multicolumn{6}{|c|}{ Retorno ocorrido } \\
\hline & & $\begin{array}{c}\text { RF e RM } \\
1996-2006\end{array}$ & $\begin{array}{c}12 \text { meses } \\
\text { depois em US\$ }\end{array}$ & $\begin{array}{c}24 \text { meses } \\
\text { depois em US\$ }\end{array}$ & $\begin{array}{c}36 \text { meses } \\
\text { depois em US\$ }\end{array}$ & $\begin{array}{c}12 \text { meses } \\
\text { depois em R\$ }\end{array}$ & $\begin{array}{c}24 \text { meses } \\
\text { depois em R\$ }\end{array}$ & $\begin{array}{c}36 \text { meses } \\
\text { depois em R\$ }\end{array}$ \\
\hline Natura & $26 / 05 / 04$ & 0,149 & 1,731 & 1,276 & 0,854 & 1,070 & 0,922 & 0,577 \\
\hline Gol & $24 / 06 / 04$ & 0,161 & 0,753 & 0,999 & 0,591 & 0,339 & 0,687 & 0,356 \\
\hline \multirow{5}{*}{ 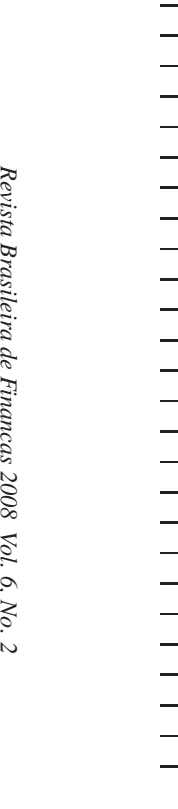 } & $25 / 06 / 04$ & 0,151 & 0,670 & 1,004 & 0,947 & 0,283 & 0,698 & 0,664 \\
\hline CPFL Energia & $29 / 09 / 04$ & 0,128 & 0,884 & 0,562 & & 0,461 & 0,359 & \\
\hline Grendene & $29 / 10 / 04$ & 0,131 & $-0,251$ & $-0,087$ & & $-0,411$ & $-0,210$ & \\
\hline & 19/11/04 & 0,132 & 1,551 & 0,731 & & 1,050 & 0,533 & \\
\hline Porto Seguro & $22 / 11 / 04$ & 0,101 & 0,887 & 1,031 & & 0,537 & 0,796 & \\
\hline Renar Macas & $28 / 02 / 05$ & 0,129 & $-0,433$ & $-0,217$ & & $-0,544$ & $-0,297$ & \\
\hline & $30 / 03 / 05$ & 0,195 & 1,997 & 1,210 & & 1,434 & 0,925 & \\
\hline & $23 / 05 / 05$ & 0,132 & 2,771 & 1,799 & & 2,480 & 1,497 & \\
\hline Energias BR & $13 / 07 / 05$ & 0,122 & 0,685 & 0,722 & & 0,595 & 0,540 & \\
\hline & $15 / 07 / 05$ & 0,126 & 0,294 & 0,600 & & 0,222 & 0,427 & \\
\hline Cosan & $18 / 11 / 05$ & 0,116 & 1,377 & & & 1,353 & & \\
\hline Universo Online & $16 / 12 / 05$ & 0,172 & $-0,317$ & & & $-0,361$ & & \\
\hline Vivax & $08 / 02 / 06$ & 0,132 & 0,938 & & & 0,197 & & \\
\hline Copasa MG & 08/02/06 & 0,103 & 0,249 & & & 0,857 & & \\
\hline Gafisa & $17 / 02 / 06$ & 0,109 & 0,948 & & & 0,914 & & \\
\hline Company & $02 / 03 / 06$ & 0,107 & 0,394 & & & 0,400 & & \\
\hline Totvs & $09 / 03 / 06$ & 0,153 & 0,816 & & & 0,750 & & \\
\hline Equatorial & $03 / 04 / 06$ & 0,103 & 0,391 & & & 0,304 & & \\
\hline American Banknote & $27 / 04 / 06$ & 0,183 & 0,186 & & & 0,135 & & \\
\hline CSU CardSystem & $02 / 05 / 06$ & 0,195 & $-0,342$ & & & $-0,362$ & & \\
\hline Lupatech & $15 / 05 / 06$ & 0,112 & 0,993 & & & 0,863 & & \\
\hline GP Investments & $01 / 06 / 06$ & 0,095 & 1,622 & & & 1,172 & & \\
\hline Datasul & $02 / 06 / 06$ & 0,151 & 0,623 & & & 0,373 & & \\
\hline Média & & 0,136 & 0,777 & 0,803 & 0,797 & 0,564 & 0,573 & 0,533 \\
\hline
\end{tabular}

\begin{tabular}{l|l} 
Média & \\
*No caso da Natura, 0,149 significa
\end{tabular}

dos primeiros 12 meses após o IPO. 
Os resultados acima provavelmente se devem ao período analisado, marcado pelos elevados retornos apresentados no mercado bursátil brasileiro. Soma-se a isto o fato de a moeda local (Real) ter se valorizado significativamente frente ao dólar. O retorno do IBRX 100 no período foi de 219,2\%, enquanto a variação cambial foi de $-38 \%$.

Tabela 11

Testes estatísticos para retornos

\begin{tabular}{c|c|c|c|c|c|c|c}
\hline Teste & Descrição & Premissas & $\begin{array}{c}\text { Objeto do } \\
\text { estudo }\end{array}$ & Hipóteses & $\begin{array}{c}\text { Nível de } \\
\text { significância }\end{array}$ & $\begin{array}{c}\text { Estatística de } \\
\text { teste }\end{array}$ & Conclusão \\
\hline Média & $\begin{array}{c}\text { Teste } t \text { para } \\
\text { médias de } \\
\text { amostras } \\
\text { pequenas } \\
\text { dependentes }\end{array}$ & $\begin{array}{c}\text { Populações } \\
\text { possuem } \\
\text { distribuição } \\
\text { normal }\end{array}$ & Retornos & $\begin{array}{c}\text { H0: retorno ocorrido }= \\
\text { retorno modelo }\end{array}$ & 0,05 & 3,1554 & $\begin{array}{c}\text { Há evidências de que } \\
\text { o retorno ocorrido } \\
\text { é maior que } \\
\text { o retorno do modelo }\end{array}$ \\
\cline { 3 - 6 } & $\begin{array}{c}\text { H1: retorno ocorrido }> \\
\text { retorno modelo }\end{array}$ & & & & & & \\
\hline
\end{tabular}

Em seguida, comparando-se os betas utilizados no modelo e os betas verificados 12 meses após a IPO, verificou-se que a média dos betas de 12 meses é estatisticamente superior à média dos betas do modelo. Ou seja, considerando-se que os betas das empresas após 12 meses de negociação sejam eficientes aproximações para os seus betas reais, analistas de mercado que utilizassem betas médios de setores para precificação de IPOs estariam cometendo um grave erro de avaliação. Novamente, são expostos resultados de 24 meses e 36 meses, apesar do pequeno número de observações (doze e três observações, respectivamente). 
Tabela 12

Betas do modelo $\mathrm{x}$ betas futuros

\begin{tabular}{|c|c|c|c|c|c|}
\hline Empresa & Data da IPO & Beta (IPO) & Beta 12 meses & Beta 24 meses & Beta 36 meses \\
\hline Natura & $26 / 05 / 04$ & 0,67 & 1,00 & 1,40 & 1,80 \\
\hline Gol & $24 / 06 / 04$ & 0,87 & 1,30 & 1,70 & 1,90 \\
\hline ALL America Latina & $25 / 06 / 04$ & 0,61 & 1,30 & 1,00 & 0,90 \\
\hline CPFL Energia & $29 / 09 / 04$ & 0,50 & 0,90 & 1,20 & \\
\hline Grendene & $29 / 10 / 04$ & 0,70 & 1,60 & 1,50 & \\
\hline Dasa & $19 / 11 / 04$ & 0,72 & 1,90 & 1,50 & \\
\hline Porto Seguro & $22 / 11 / 04$ & $-0,08$ & 0,70 & 0,90 & \\
\hline Renar Macas & $28 / 02 / 05$ & 0,78 & 1,40 & 1,40 & \\
\hline Submarino & $30 / 03 / 05$ & 2,55 & 1,30 & 1,70 & \\
\hline Localiza & $23 / 05 / 05$ & 0,78 & 1,40 & 1,80 & \\
\hline Energias BR & $13 / 07 / 05$ & 0,61 & 1,20 & 1,70 & \\
\hline OHL Brasil & $15 / 07 / 05$ & 0,72 & 2,50 & 2,10 & \\
\hline Cosan & $18 / 11 / 05$ & 0,61 & 2,10 & & \\
\hline Universo Online & $16 / 12 / 05$ & 2,09 & 1,90 & & \\
\hline Vivax & $08 / 02 / 06$ & 1,25 & 1,90 & & \\
\hline Copasa MG & $08 / 02 / 06$ & 0,51 & 1,40 & & \\
\hline Gafisa & $17 / 02 / 06$ & 0,67 & 2,20 & & \\
\hline Company & $02 / 03 / 06$ & 0,73 & 2,10 & & \\
\hline Totvs & $09 / 03 / 06$ & 1,92 & 1,60 & & \\
\hline Equatorial & $03 / 04 / 06$ & 0,60 & 1,50 & & \\
\hline American Banknote & $27 / 04 / 06$ & 2,66 & 1,30 & & \\
\hline CSU CardSystem & $02 / 05 / 06$ & 3,00 & 0,70 & & \\
\hline Lupatech & $15 / 05 / 06$ & 0,85 & 1,40 & & \\
\hline GP Investments & $01 / 06 / 06$ & 0,29 & 0,80 & & \\
\hline Datasul & $02 / 06 / 06$ & 1,75 & 1,60 & & \\
\hline Média & & 1,05 & 1,48 & 1,49 & 1,53 \\
\hline
\end{tabular}

Fonte: Economática.

Tabela 13

Testes estatísticos para retornos

\begin{tabular}{c|c|c|c|c|c|c|c}
\hline Teste & Descrição & Premissas & $\begin{array}{c}\text { Objeto do } \\
\text { estudo }\end{array}$ & Hipóteses & $\begin{array}{c}\text { Nível de } \\
\text { significância }\end{array}$ & $\begin{array}{c}\text { Estatística de } \\
\text { teste }\end{array}$ & Conclusão \\
\hline Média & $\begin{array}{c}\text { Teste } t \text { para } \\
\text { médias de } \\
\text { amostras } \\
\text { pequenas } \\
\text { dependentes }\end{array}$ & $\begin{array}{c}\text { Populações } \\
\text { possuem } \\
\text { distribuição } \\
\text { normal }\end{array}$ & Betas & $\begin{array}{c}\text { H0: beta 12 meses } \\
\text { beta modelo }\end{array}$ & 0,05 & 2,049 & $\begin{array}{c}\text { Há evidências de que } \\
\text { o retorno ocorrido } \\
\text { é maior que } \\
\text { o retorno do modelo }\end{array}$ \\
\hline
\end{tabular}

\section{Conclusões}

\subsection{Conclusões gerais}

O mercado de capitais brasileiro vem passando por um período distinto em sua história. Diversos fatores corroboram um cenário mais estável para o desenvolvimento de um mercado bursátil sustentável e sólido. Conseqüentemente, cresce o número de empresas interessadas em aproveitar os benefícios oriundos da abertura de capital. 
A expansão do número de IPOs tem gerado interesse em relação às premissas adotadas na precificação das ações. Ao analisar a precificação em IPOs, este trabalho abordou alguns dos elementos essenciais no momento em que a empresa faz sua primeira emissão de ações.

Após a verificação de elevados retornos inicias e baixos retornos de longo prazo, para a amostra em questão, foi utilizada a avaliação por múltiplos, buscando-se verificar se as empresas da amostra estavam sub-avaliadas ou superavaliadas. Ressalta-se que foram utilizados resultados futuros e não projeções realizadas no momento da IPO. ${ }^{12}$

Verificou-se que tanto a média como a mediana da amostra composta por empresas estreantes são maiores do que as respectivas medidas de posição da amostra de empresas similares listadas em bolsa. No entanto, ao realizar testes estatísticos para diferença de médias e medianas, não foi encontrada significância estatística do resultado.

Esse resultado corrobora a teoria de Leal (1991) sobre a existência de uma bolha especulativa nas IPOs. Ou seja, as avaliações foram corretas, porém os preços esperados pelo mercado estavam inflados. Ao citar a teoria da bolha especulativa, Tiniç (1988) ressalta que os elevados retornos são provenientes da elevada demanda inicial de investidores que não conseguiriam as quantidades de ações que desejaram. Mesmo estreando no mercado com preços elevados, as empresas da amostra apresentaram elevados retornos iniciais.

Finalmente, comprovou-se estatisticamente que os betas das empresas após 12 meses de negociação são significativamente superiores aos betas utilizados no modelo CAPM, no momento da IPO. A utilização de betas mais elevados no modelo elevaria o custo de capital próprio da empresa. Conseqüentemente, reduziria o valor presente dos fluxos de caixa descontados no momento da IPO. Ou seja, o valor da empresa ou do patrimônio líquido (valor de mercado) calculados seriam menores, resultando em um menor preço por ação.

Como esperado, os retornos ocorridos após a IPO (período de 12 meses) foram significativamente superiores ao custo de capital do acionista determinado na abertura de capital (as comparações foram feitas em dólar). O elevado retorno em dólar é explicado não só pelo alto retorno das ações em real, como pelo fato de a moeda nacional ter-se valorizado frente ao dólar, gerando retornos ainda maiores.

\subsection{Limitações do trabalho}

A avaliação por múltiplos é mais complexa no caso de países que não apresentam muitas empresas listadas em bolsa, como no Brasil. No momento da abertura de capital da Natura, por exemplo, não existiam empresas brasileiras comparáveis negociadas na Bovespa. Essa escassez, que tem sido reduzida com o passar dos anos, no entanto, influenciou a pesquisa realizada.

\footnotetext{
${ }^{12}$ A utilização do Lucro e EBIT verificados após a IPO pode gerar distorções na análise de precificação. A utilização de projeções realizadas no período da IPO pode gerar resultados distintos dos encontrados neste trabalho.
} 
Para a determinação de múltiplos comparáveis foram adotados ajustes e aproximações que podem gerar resultados questionáveis.

A utilização da classificação NAICS (nível 2), disponível no Economática, também deve ser citada, já que em alguns casos agrega em um mesmo setor empresas pouco similares.

Por fim, a questão do tamanho da amostra também é relevante para a realização de uma pesquisa exploratória.

\subsection{Sugestões para pesquisas futuras}

Este trabalho limitou-se a um período de dois anos de análise, em virtude da recente expansão dos processos de emissão pública inicial. Conseqüentemente, para a análise de custo de capital próprio e dos múltiplos, no caso de empresas brasileiras, foi utilizada uma amostra relativamente pequena, composta por $25 \mathrm{em}$ presas. Quando os índices PL e EVEBIT foram analisados separadamente, as amostras foram reduzidas ainda mais, para 23 e 22 empresas, respectivamente.

Quanto à análise de múltiplos, seria relevante a utilização de uma amostra maior, essencial para analisar diferenças entre os múltiplos utilizados nos diferentes anos e diversos setores, assim como para a verificação de relações entre precificação e retorno.

Quanto à determinação do custo de capital do acionista, sugere-se, para pesquisas futuras, a verificação de betas de 60 meses (mais estáveis) e sua comparação com os betas utilizados no momento da IPO. Das 25 empresas estudadas, 12 possuem betas de 24 meses e apenas 3 possuem betas de 36 meses.

O ano de 2007 será encerrado com número recorde de IPOs realizados no Brasil. A tendência para os próximos anos é de novos recordes, o que possibilitará estudos mais detalhados e consistentes a respeito do assunto.

\section{Referências}

Aggarwal, R., Leal, R., \& Hernandez, L. (1993). The after-market performance of initial public offerings in Latin America. Financial Management, 22:42-53.

Alford, A. W. (1992). The effect of the set of comparable firms on the accuracy of the price-earnings valuation method. Journal of Accounting Research, 30(1):94-108.

Baker, M. \& Ruback, R. S. (1999). Estimating industry multiples. Harvard. Business School Working Paper, 1999. Disponivel em: http://www.people.hbs.edu/mbaker/cv/papers/EstimatingIndustry.pdf. Acesso em 28 de Junho de 2008.

Bhojraj, S. \& Lee, C. M. C. (2002). Who is my peer? A valuationbased approach to the selection of comparable firms. Journal of Accounting Research, 40:407439. 
Bovespa (2007a). Como e por que tornar-se uma cia aberta. Guia Bovespa. Disponível em: www.bovespa.com.br. Acesso em 20 de Março de 2007.

Bovespa (2007b). Custo da abertura de capital e manutenção da cia. aberta. Guia Bovespa. Disponível em: www.bovespa.com.br. Acesso em 20 de Março de 2007.

Bovespa (2007c). Estatísticas das aberturas de capital na BOVESPA. Disponível em: www.bovespa.com.br. Acesso em 20 de Março de 2007.

Bovespa (2007d). Participação dos investidores estrangeiros em distribuições públicas. Disponível em: http://www.bovespa.com.br/Mercado/RendaVariavel/ PartInvest/IndexP.asp. Acesso em 20 de Março de 2007.

Brigham, E. F., Gapenski, L. C., \& Ehrhardt, M. C. (2001). Administração Financeira: Teoria e Prática. Atlas, São Paulo.

Chi, J. \& Padgett, C. (2005). The performance and long-run characteristics of the Chinese IPO market. Pacific Economic Review, 10:451-69.

Comissão de Valores Mobiliários (2007). Mercado de capitais e o papel da CVM. Disponível em: www.unifacs.br/graduacao/cursos/economia/downloads /Mercado\%20de\%20capitais.ppt. Acesso em 5 de Abril de 2007.

Damodaran, A. (1999). The dark side of valuation: Firms with no earnings, no history and no comparables. Stern School of Business Working Paper. Disponivel em: http://www.stern.nyu.edu/fin/workpapers/papers99/wpa99022.pdf. Acesso em 25 de Maio de 2007.

Damodaran, A. (2003). Avaliação de Investimentos: Ferramentas e Técnicas Para a Determinação Do Valor de Qualquer Ativo. Qualitymark, Rio de Janeiro. Trad. Carlos Henrique Trieschmann e Ronaldo de Almeida Rego.

Dittmann, I. \& Weiner, C. (2005). Selecting comparables for the valuation of european firms. Disponível em: http://ssrn.com/abstract=644101. Acesso em 28 de Junho de 2008.

Famá, R. \& Santiago Filho, J. L. (2001). Avaliação de empresas através de múltiplos: Uma comparação entre as empresas do Brasil e dos EUA. In Seminários Em Administração FEA/USP - SEMEAD V Anais. FEA/USP, São Paulo.

Firth, M. (1998). IPO profit forecasts and their role in signalling firm value and explaining post-listing returns. Applied Financial Economics, 8:29-39.

Gunther, S. \& Rummer, M. (2006). The hot-issue period in Germany: What factors drove IPO underpricing? In Gregoriou, G. N., editor, Initial Public Offerings: An International Perspective. Elsevier, Burlington. 
Harvey, C. (2001). The international cost of capital and risk calculator. Disponível em: http://faculty.fuqua.duke.edu/c̃harvey/Research/Working_Papers/ W35_The_int ernational_cost.pdf. Acesso em 15 de Janeiro de 2007.

How, J., Lam, J., \& Yeo, J. (2007). The use of the comparable firm approach in valuing Australian IPOs. International Review of Financial Analysis, 16(2):99115 .

Ibbotson, R. G. (1975). Price performance of common stock new issues. Journal of Financial Economics, 2(Disponível em: http://www.sciencedirect.com/. Acesso em 15 de Janeiro de 2007.):235-272.

Ibbotson, R. G. \& Jaffe, J. F. (1975). "hot issues" markets. Journal of Finance, 30(4):1027-1042.

Kim, M. \& Ritter, J. R. (1999). Valuing IPOs. Journal of Financial Economics, 53:409-437.

Leal, R. P. C. (1991). Por que há retornos anormais nas aberturas de capital? Revista de Administração, 26(4):107-112.

Leal, R. P. C. (2002). Revisão da literatura sobre estimativa de custo de capital aplicada ao Brasil. Rio de Janeiro: COPPEAD/UFRJ (não publicado). Disponível em: http://ricardoleal.wikispaces.com/space/showimage/ FIPE+-+ Revis\%C3\%A3o+de+literatura+custo+de+capital+3.pdf. Acesso em: 05 de Fevereiro de 2007.

Lintner, J. (1965). The valuation of risk assets and the selection of risky investments in stock portfolios and capital budgets. Review of Economics and Statistics, 47(1):13-37.

Liu, J., Nissim, D., \& Thomas, J. (2002). Equity valuation using multiples. Journal of Accounting Research, pages 135-171.

Ljungqvist, A. (2004). IPO underpricing. Handbooks in Finance: Empirical Corporate Finance, Chapter III.4: September 1, 2004. Disponível em: http://papers.ssrn.com/sol3/papers.cfm?abstractid=609422. Acesso em 20 de Março de 2007.

Logue, D. (1973). On the pricing of unseasoned equity issues 1965-1969. Journal of Financial and Quantitative Analyse, 8:91-103.

Loughran, T., Ritter, J., \& Rydqvist, K. (1994). Initial public offerings: International insights. Pacific-Basin Finance Journal, 2:165-199. Disponível em: http://bear.cba.ufl.edu/ritter/Int2007.pdf. Acesso em 20 de Fevereiro de 2007. 
Loughran, T. \& Ritter, J. R. (1995). The new issues puzzle. The Journal of Finance, 50(1):23-51. Disponível em: http://www.jstor.org. Acesso em 05 de Fevereiro de 2007.

Loughran, T. \& Ritter, J. R. (2002). Why has IPO underpricing changed over time? The Journal of Finance. Disponível em: http://www.jstor.org. Acesso em 05 de Fevereiro de 2007.

McCarthy, E. (1999). Pricing IPOs: Science or science fiction? Journal of Accountancy New York, 58(3).

McClave, J. T., Benson, P. G., \& Sincich, T. (2000). Statistics for Business and Economics. Prentice-Hall, 8 edition.

Minardi, A., Sanvicente, A. Z., Montenegro, C. M. G., Donatelli, D. H., \& Bignotto, F. G. (2007). Estimando o custo de capital de companhinas fechadas no Brasil para uma melhor gestão estratégica de projetos. Ibmec Working Paper WPE, n. 33. Disponível em www.ibmecsp.edu.br. Acesso em 15 de fevereiro de 2007.

Mossin, J. (1966). Equilibrium in a capital asset market. Econometrica, 34(4):768-783.

Ness, W. L. \& Pereira, R. F. (1980). O mercado primário de ações no Brasil. Rio de Janeiro: Documento de Trabalho IBMEC, p. 500.

O’Hanlon, J., Peasnell, K., \& Peng, B. (2007). Valuation anchors and premium multiples. Working paper presented at the 2006 BAA Doctoral Colloquium, 2007. Disponivel em: http://www.baa.group.shef.ac.uk/events/conference/ 2008/papers/ohanlon.pdf. Acesso em 28 de Junho de 2008.

Pereiro, L. E. (2001). The valuation of closely-held companies in Latin America. Emerging Markets Review, 2:330-370.

Procianoy, J. L. \& Cigerza, G. C. (2007). IPOs in emerging markets: A comparison of Brazil, India and China. Working Paper Series, 2007. Disponível em SSRN Electronic Paper Collection : http://ssrn.com/abstract=968300. Acesso em 5 de Abril de 2007.

Reilly, F. K. (1993). Further evidence on short-run results for new issue investors. The Journal of Financial and Quantitative Analysis, 8(1):83-90.

Ritter, J. R. (1991). The long-run performance of initial public offerings. Journal of Finance, 46(1):3-27. Disponível em: http://ideas.repec.org/a/bla/jfinan/ v46y1991i1p3-27.html. Acesso em 25 de Março de 2007. 
Ritter, J. R. (2006). Money left on the table in IPOs by firm. Disponível em: http://bear.cba.ufl.edu/ritter/work_papers/monew.pdf. Acesso em 25 de Março de 2007.

Ritter, J. R. \& Welch, I. (2002). A review of IPO activity, pricing and allocations. Yale International Center for Finance, Working Paper No. 02-01, 2002. Disponível em http://leeds-faculty.colorado.edu/Bhagat/IPO-review.pdf. Acesso em: 20 de março de 2007.

Sharpe, W. F. (1964). Capital asset prices: A theory of market equilibrium under conditions of risk. Journal of Financial Economics, 19(3):425-442.

Stoll, H. R. \& Curley, A. J. (1970). Small business and the new issues market for equities. Journal of Financial and Quantitative Analysis, 5:309-322.

Tiniç, S. M. (1988). Anotomy of initial public offerings of common stock. The Journal of Finance, 43:789-822. Disponível em http://www.jstor.org. Acesso em 04 de Fevereiro de 2007.

Toniato, J. B. A. (2007). Hot issue no mercado de IPO e as consequências para as empresas emitentes e investidores: O mercado do Reino Unido em 2000. Brazilian Business Review, 4(1):1-25.

Treynor, J. (1961). Toward a theory of the market value of risky assets. Artigo não publicado. 


\section{Apêndice}

Tabela A.1

Modelo Goldman

\begin{tabular}{l|c|c|c|c|c|c|c}
\hline \multicolumn{7}{c}{ Empresas } & \multicolumn{7}{c}{ Data do IPO } & RF & RP & Beta & RM & $\begin{array}{c}\text { Prêmio } \\
\text { de Mercado }\end{array}$ & $k e(U S \$)$ \\
\hline & & & & & & \\
\hline & & $\begin{array}{c}\text { BOND 10 anos } \\
1996-2006\end{array}$ & Risco País & B leverage & $\begin{array}{c}\text { S\&P 500 } \\
1996-2006\end{array}$ & RM - RF & $\begin{array}{c}\text { RF e RM } \\
1996-2006\end{array}$ \\
\hline Natura & $26 / 05 / 04$ & 0,0567 & 0,066 & 0,665 & 0,096 & 0,039 & 0,149 \\
\hline Gol & $24 / 06 / 04$ & 0,0567 & 0,070 & 0,875 & 0,096 & 0,039 & 0,161 \\
\hline ALL America Latina & $25 / 06 / 04$ & 0,0567 & 0,070 & 0,614 & 0,096 & 0,039 & 0,151 \\
\hline CPFL Energia & $29 / 09 / 04$ & 0,0567 & 0,052 & 0,501 & 0,096 & 0,039 & 0,128 \\
\hline Grendene & $29 / 10 / 04$ & 0,0567 & 0,047 & 0,704 & 0,096 & 0,039 & 0,131 \\
\hline Dasa & $19 / 11 / 04$ & 0,0567 & 0,047 & 0,720 & 0,096 & 0,039 & 0,132 \\
\hline Porto Seguro & $22 / 11 / 04$ & 0,0567 & 0,047 & $-0,083$ & 0,096 & 0,039 & 0,101 \\
\hline Renar Macas & $28 / 02 / 05$ & 0,0567 & 0,042 & 0,783 & 0,096 & 0,039 & 0,129 \\
\hline Submarino & $30 / 03 / 05$ & 0,0567 & 0,039 & 2,554 & 0,096 & 0,039 & 0,195 \\
\hline Localiza & $23 / 05 / 05$ & 0,0567 & 0,045 & 0,777 & 0,096 & 0,039 & 0,132 \\
\hline Energias BR & $13 / 07 / 05$ & 0,0567 & 0,041 & 0,606 & 0,096 & 0,039 & 0,122 \\
\hline OHL Brasil & $15 / 07 / 05$ & 0,0567 & 0,041 & 0,720 & 0,096 & 0,039 & 0,126 \\
\hline Cosan & $18 / 11 / 05$ & 0,0567 & 0,036 & 0,613 & 0,096 & 0,039 & 0,116 \\
\hline Universo Online & $16 / 12 / 05$ & 0,0567 & 0,034 & 2,090 & 0,096 & 0,039 & 0,172 \\
\hline Vivax & $08 / 02 / 06$ & 0,0567 & 0,027 & 1,246 & 0,096 & 0,039 & 0,132 \\
\hline Copasa MG & $08 / 02 / 06$ & 0,0567 & 0,027 & 0,512 & 0,096 & 0,039 & 0,103 \\
\hline Gafisa & $17 / 02 / 06$ & 0,0567 & 0,027 & 0,666 & 0,096 & 0,039 & 0,109 \\
\hline Company & $02 / 03 / 06$ & 0,0567 & 0,022 & 0,728 & 0,096 & 0,039 & 0,107 \\
\hline Totvs & $09 / 03 / 06$ & 0,0567 & 0,022 & 1,917 & 0,096 & 0,039 & 0,153 \\
\hline Equatorial & $03 / 04 / 06$ & 0,0567 & 0,023 & 0,599 & 0,096 & 0,039 & 0,103 \\
\hline American Banknote & $27 / 04 / 06$ & 0,0567 & 0,023 & 2,655 & 0,096 & 0,039 & 0,183 \\
\hline CSU CardSystem & $02 / 05 / 06$ & 0,0567 & 0,022 & 3,000 & 0,096 & 0,039 & 0,195 \\
\hline Lupatech & $15 / 05 / 06$ & 0,0567 & 0,022 & 0,855 & 0,096 & 0,039 & 0,112 \\
\hline GP Investments & $01 / 06 / 06$ & 0,0567 & 0,027 & 0,294 & 0,096 & 0,039 & 0,095 \\
\hline Datasul & $02 / 06 / 06$ & 0,0567 & 0,027 & 1,746 & 0,096 & 0,039 & 0,151 \\
\hline & & & & & & & \\
\hline Média & & & & & & & 0,136 \\
\hline & & & & & & & \\
\hline
\end{tabular}


Tabela A.2

Cálculo do beta

\begin{tabular}{l|c|c|c|c|c}
\hline Empresa & Data da IPO & Bu do Setor & Imposto de Renda & D/E * & Beta (IPO) \\
\hline Natura & $26 / 05 / 04$ & 0,670 & 0,340 & $-0,011$ & 0,665 \\
\hline Gol & $24 / 06 / 04$ & 0,950 & 0,340 & $-0,120$ & 0,875 \\
\hline ALL America Latina & $25 / 06 / 04$ & 0,580 & 0,340 & 0,088 & 0,614 \\
\hline CPFL Energia & $29 / 09 / 04$ & 0,420 & 0,340 & 0,292 & 0,501 \\
\hline Grendene & $29 / 10 / 04$ & 0,780 & 0,340 & $-0,148$ & 0,704 \\
\hline Dasa & $19 / 11 / 04$ & 0,700 & 0,340 & 0,043 & 0,720 \\
\hline Porto Seguro & $22 / 11 / 04$ & 0,770 & 0,340 & $-1,678$ & $-0,083$ \\
\hline Renar Macas & $28 / 02 / 05$ & 0,540 & 0,340 & 0,680 & 0,783 \\
\hline Submarino & $30 / 03 / 05$ & 2,890 & 0,340 & $-0,176$ & 2,554 \\
\hline Localiza & $23 / 05 / 05$ & 0,730 & 0,340 & 0,097 & 0,777 \\
\hline Energias BR & $13 / 07 / 05$ & 0,460 & 0,340 & 0,480 & 0,606 \\
\hline OHL Brasil & $15 / 07 / 05$ & 0,640 & 0,340 & 0,190 & 0,720 \\
\hline Cosan & $18 / 11 / 05$ & 0,500 & 0,340 & 0,342 & 0,613 \\
\hline Universo Online & $16 / 12 / 05$ & 2,570 & 0,340 & $-0,283$ & 2,090 \\
\hline Vivax & $08 / 02 / 06$ & 1,200 & 0,340 & 0,059 & 1,246 \\
\hline Copasa MG & $08 / 02 / 06$ & 0,480 & 0,340 & 0,100 & 0,512 \\
\hline Gafisa & $17 / 02 / 06$ & 0,680 & 0,340 & $-0,032$ & 0,666 \\
\hline Company & $02 / 03 / 06$ & 0,680 & 0,340 & 0,107 & 0,728 \\
\hline Totvs & $09 / 03 / 06$ & 2,000 & 0,340 & $-0,063$ & 1,917 \\
\hline Equatorial & $03 / 04 / 06$ & 0,510 & 0,340 & 0,263 & 0,599 \\
\hline American Banknote & $27 / 04 / 06$ & 2,730 & 0,340 & $-0,041$ & 2,655 \\
\hline CSU CardSystem & $02 / 05 / 06$ & 2,730 & 0,340 & 0,150 & 3,000 \\
\hline Lupatech & $15 / 05 / 06$ & 0,810 & 0,340 & 0,084 & 0,855 \\
\hline GP Investments & $01 / 06 / 06$ & 0,340 & 0,340 & $-0,206$ & 0,294 \\
\hline Datasul & $02 / 06 / 06$ & 2,000 & 0,340 & $-0,192$ & 1,746 \\
\hline & & & & & \\
\hline Média & & & & 0,001 & 1,054 \\
\hline$*$ Alguns & & & & & \\
\hline
\end{tabular}

* Algumas empresas possuem dívida líquida negativa, em função do elevado valor

disponível em caixa. Com isso, o indicador D/E (Dívida Líquida/Patrimônio Líquido)

pode apresentar resultados negativos. 
Tabela A.3

Modelo Goldman para diferentes retornos de mercado e taxas livres de risco

CAPM Goldman

\begin{tabular}{|c|c|c|c|c|c|c|c|c|c|c|c|c|}
\hline \multicolumn{13}{|c|}{ CAPM Goldman } \\
\hline \multirow{3}{*}{ Empresas } & \multirow{3}{*}{ Data do IPO } & \multicolumn{3}{|c|}{$\mathrm{RF}$} & \multicolumn{2}{|c|}{\begin{tabular}{|l|l|} 
Risco País & Beta \\
\end{tabular}} & \multicolumn{3}{|c|}{ RM } & \multicolumn{3}{|c|}{ Custo do Capital Próprio } \\
\hline & & TBOND 10 anos & TBOND 10 anos & TBOND 10 anos & Risco País & \begin{tabular}{|l|} 
Beta \\
\end{tabular} & S\&P 500 & S\&P 500 & S\&P 500 & RF e RM & RF e RM & RF e RM \\
\hline & & 1996-2006 & $1966-2006$ & $1928-2006$ & na IPO & (IPO) & $1996-2006$ & 1966-2006 & 1928-2006 & 1996-2006 & 1966-2006 & 1928-2006 \\
\hline Natura & $26 / 05 / 04$ & 0,057 & 0,071 & 0,050 & 0,066 & 0,665 & 0,096 & 0,103 & 0,099 & 0,149 & 0,159 & 0,148 \\
\hline Gol & $24 / 06 / 04$ & 0,057 & 0,071 & 0,050 & 0,070 & \begin{tabular}{|l|}
0,875 \\
\end{tabular} & 0,096 & 0,103 & 0,099 & 0,161 & 0,169 & 0,163 \\
\hline ALL America Latina & $25 / 06 / 04$ & 0,057 & 0,071 & 0,050 & 0,070 & \begin{tabular}{|l|}
0,614 \\
\end{tabular} & 0,096 & 0,103 & 0,099 & 0,151 & 0,161 & 0,150 \\
\hline CPFL Energia & 29/09/04 & 0,057 & 0,071 & 0,050 & 0,052 & \begin{tabular}{|l|}
0,501 \\
\end{tabular} & 0,096 & 0,103 & 0,099 & 0,128 & 0,139 & 0,126 \\
\hline Grendene & $29 / 10 / 04$ & 0,057 & 0,071 & 0,050 & 0,047 & \begin{tabular}{|l|}
0,704 \\
\end{tabular} & 0,096 & 0,103 & 0,099 & 0,131 & 0,141 & 0,131 \\
\hline Dasa & $19 / 11 / 04$ & 0,057 & 0,071 & 0,050 & 0,047 & \begin{tabular}{|l|}
0,720 \\
\end{tabular} & 0,096 & 0,103 & 0,099 & 0,132 & 0,142 & 0,132 \\
\hline Porto Seguro & $22 / 11 / 04$ & 0,057 & $\overline{0,071}$ & 0,050 & 0,047 & $-0,083$ & 0,096 & 0,103 & 0,099 & 0,101 & 0,115 & 0,093 \\
\hline Renar Macas & $28 / 02 / 05$ & 0,057 & 0,071 & 0,050 & 0,042 & \begin{tabular}{|l|}
0,783 \\
\end{tabular} & 0,096 & 0,103 & 0,099 & 0,129 & 0,138 & 0,130 \\
\hline Submarino & $30 / 03 / 05$ & 0,057 & 0,071 & 0,050 & 0,039 & \begin{tabular}{|l|}
2,554 \\
\end{tabular} & 0,096 & 0,103 & 0,099 & 0,195 & 0,193 & 0,214 \\
\hline Localiza & $23 / 05 / 05$ & 0,057 & 0,071 & 0,050 & 0,045 & \begin{tabular}{|l|}
0,777 \\
\end{tabular} & 0,096 & 0,103 & 0,099 & 0,132 & 0,141 & 0,133 \\
\hline Energias BR & $13 / 07 / 05$ & 0,057 & 0,071 & 0,050 & 0,041 & \begin{tabular}{|l|}
0,606 \\
\end{tabular} & 0,096 & 0,103 & $\overline{0,099}$ & 0,122 & 0,132 & 0,121 \\
\hline OHL Brasil & $15 / 07 / 05$ & 0,057 & 0,071 & 0,050 & 0,041 & 0,720 & 0,096 & 0,103 & 0,099 & 0,126 & 0,136 & 0,126 \\
\hline Cosan & $18 / 11 / 05$ & 0,057 & 0,071 & 0,050 & 0,036 & 0,613 & 0,096 & 0,103 & 0,099 & 0,116 & 0,126 & 0,115 \\
\hline Universo Online & $16 / 12 / 05$ & 0,057 & 0,071 & 0,050 & 0,034 & 2,090 & 0,096 & 0,103 & 0,099 & 0,172 & 0,173 & 0,186 \\
\hline Vivax & $08 / 02 / 06$ & 0,057 & 0,071 & 0,050 & 0,027 & 1,246 & 0,096 & 0,103 & 0,099 & 0,132 & 0,138 & 0,137 \\
\hline Copasa MG & $08 / 02 / 06$ & 0,057 & 0,071 & 0,050 & 0,027 & 0,512 & 0,096 & 0,103 & 0,099 & 0,103 & 0,114 & 0,101 \\
\hline Gafisa & $17 / 02 / 06$ & 0,057 & 0,071 & 0,050 & 0,027 & \begin{tabular}{|l|}
0,666 \\
\end{tabular} & 0,096 & 0,103 & 0,099 & 0,109 & 0,119 & 0,109 \\
\hline Company & $02 / 03 / 06$ & 0,057 & 0,071 & 0,050 & 0,022 & \begin{tabular}{|l|}
0,728 \\
\end{tabular} & 0,096 & 0,103 & 0,099 & 0,107 & 0,117 & 0,107 \\
\hline Totvs & $09 / 03 / 06$ & 0,057 & 0,071 & 0,050 & 0,022 & \begin{tabular}{|l|}
1,917 \\
\end{tabular} & 0,096 & 0,103 & 0,099 & 0,153 & 0,155 & 0,166 \\
\hline Equatorial & $03 / 04 / 06$ & 0,057 & 0,071 & 0,050 & 0,023 & 0,599 & 0,096 & 0,103 & 0,099 & 0,103 & 0,114 & 0,102 \\
\hline American Banknote & $27 / 04 / 06$ & 0,057 & 0,071 & 0,050 & 0,023 & \begin{tabular}{|l|}
2,655 \\
\end{tabular} & 0,096 & 0,103 & 0,099 & 0,183 & 0,181 & 0,203 \\
\hline CSU CardSystem & $02 / 05 / 06$ & 0,057 & 0,071 & 0,050 & 0,022 & 3,000 & 0,096 & 0,103 & 0,099 & 0,195 & 0,190 & 0,219 \\
\hline Lupatech & $15 / 05 / 06$ & 0,057 & 0,071 & 0,050 & 0,022 & 0,855 & 0,096 & 0,103 & 0,099 & 0,112 & 0,120 & 0,113 \\
\hline GP Investments & $01 / 06 / 06$ & 0,057 & 0,071 & 0,050 & 0,027 & 0,294 & 0,096 & 0,103 & 0,099 & 0,095 & 0,107 & 0,091 \\
\hline Datasul & $02 / 06 / 06$ & 0,057 & 0,071 & 0,050 & 0,027 & 1,746 & 0,096 & 0,103 & 0,099 & 0,151 & 0,154 & 0,162 \\
\hline & & & & & & & & & & & & \\
\hline Média & & & & & & & & & & 0,136 & 0,143 & 0,139 \\
\hline
\end{tabular}


- Tabela A.4

¿ Retorno total amostra $\mathrm{x}$ retorno total IBRX100

\begin{tabular}{|c|c|c|c|c|c|c|c|c|c|c|c|c|c|c|c|}
\hline \multirow[t]{2}{*}{ Empresa } & \multirow[t]{2}{*}{ Data } & \multicolumn{7}{|c|}{ Retorno das Ações } & \multicolumn{7}{|c|}{ Retorno do IBRX100 no mesmo período } \\
\hline & & 1 dia & 1 mês & 2 meses & 6 meses & 12 meses & 24 meses & 36 meses & 1 dia & 1 mês & 2 meses & 6 meses & 12 meses & 24 meses & 36 meses \\
\hline Natura & $26 / 05 / 04$ & 0,156 & 0,295 & 0,468 & 0,822 & 1,070 & 0,922 & 0,577 & 0,012 & 0,075 & 0,097 & 0,353 & 0,432 & 0,530 & 0,468 \\
\hline Gol & $24 / 06 / 04$ & 0,054 & $-0,048$ & $-0,029$ & 0,637 & 0,339 & 0,687 & 0,356 & $-0,001$ & 0,022 & 0,115 & 0,351 & 0,343 & 0,401 & 0,450 \\
\hline ALL America Latina & $25 / 06 / 04$ & 0,132 & 0,129 & 0,310 & 0,677 & 0,283 & 0,698 & 0,664 & 0,003 & 0,023 & 0,126 & 0,353 & 0,368 & 0,402 & 0,451 \\
\hline CPFL Energia & $29 / 09 / 04$ & 0,001 & $-0,039$ & $-0,058$ & 0,034 & 0,461 & 0,359 & & 0,004 & 0,028 & 0,075 & 0,177 & 0,480 & 0,332 & \\
\hline Grendene & $29 / 10 / 04$ & 0,121 & 0,066 & 0,008 & $-0,434$ & $-0,411$ & $-0,210$ & & 0,008 & 0,055 & 0,146 & 0,101 & 0,406 & 0,360 & \\
\hline Dasa & 19/11/04 & 0,200 & 0,157 & 0,295 & 0,500 & 1,050 & 0,533 & & $-0,001$ & 0,073 & 0,067 & 0,080 & 0,420 & 0,385 & \\
\hline Porto Seguro & 22/11/04 & 0,064 & 0,005 & 0,164 & 0,133 & 0,537 & 0,796 & & 0,006 & 0,090 & 0,067 & 0,056 & 0,442 & 0,392 & \\
\hline Renar Macas & 28/02/05 & 0,012 & $-0,225$ & $-0,362$ & $-0,525$ & $-0,544$ & $-0,297$ & & $-0,013$ & $-0,076$ & $-0,153$ & 0,001 & 0,457 & 0,281 & \\
\hline Submarino & $30 / 03 / 05$ & 0,000 & $-0,218$ & $-0,181$ & 0,341 & 1,434 & 0,925 & & 0,020 & $-0,047$ & $-0,025$ & 0,270 & 0,553 & 0,378 & \\
\hline $\begin{array}{l}\text { Localiza } \\
\end{array}$ & $23 / 05 / 05$ & 0,000 & 0,039 & 0,227 & 1,252 & 2,480 & 1,497 & & $-0,012$ & 0,030 & 0,043 & 0,370 & 0,574 & 0,498 & \\
\hline Energias BR & 13/07/05 & 0,112 & 0,400 & 0,344 & 0,745 & 0,595 & 0,540 & & 0,010 & 0,098 & 0,160 & 0,479 & 0,450 & 0,534 & \\
\hline OHL Brasil & $15 / 07 / 05$ & \begin{tabular}{|l|}
0,011 \\
\end{tabular} & 0,062 & 0,292 & 0,611 & 0,222 & 0,427 & & $-0,021$ & 0,090 & 0,170 & 0,495 & 0,405 & 0,526 & \\
\hline Cosan & 18/11/05 & 0,158 & 0,396 & 0,708 & 2,002 & 1,353 & & & 0,000 & 0,062 & 0,180 & 0,229 & 0,355 & & \\
\hline Universo Online & $16 / 12 / 05$ & \begin{tabular}{|l|}
0,167 \\
\end{tabular} & 0,091 & $-0,129$ & $-0,361$ & $-0,361$ & & & \begin{tabular}{|l|}
0,006 \\
\end{tabular} & 0,135 & 0,185 & 0,044 & 0,344 & & \\
\hline Vivax & 08/02/06 & 0,047 & 0,006 & 0,047 & $-0,139$ & 0,197 & & & $-0,005$ & 0,005 & 0,037 & 0,022 & 0,235 & & \\
\hline Copasa MG & $08 / 02 / 06$ & $\begin{array}{ll}0,106 \\
\end{array}$ & 0,086 & 0,151 & 0,326 & 0,857 & & & $-0,005$ & 0,005 & 0,037 & 0,022 & 0,235 & & \\
\hline Gafisa & 17/02/06 & 0,295 & 0,311 & 0,135 & 0,381 & 0,914 & & & 0,005 & $-0,003$ & $-0,004$ & $-0,013$ & 0,211 & & \\
\hline Company & 02/03/06 & 0,188 & 0,119 & $-0,001$ & $-0,101$ & 0,400 & & & $-0,003$ & $-0,021$ & 0,031 & $-0,033$ & 0,090 & & \\
\hline $\begin{array}{l}\text { Totvs } \\
\end{array}$ & 09/03/06 & 0,063 & 0,161 & 0,289 & 0,235 & 0,750 & & & $-0,025$ & 0,032 & 0,130 & $-0,033$ & 0,202 & & \\
\hline Equatorial & $03 / 04 / 06$ & 0,170 & 0,055 & 0,086 & 0,103 & 0,304 & & & 0,022 & 0,075 & $-0,022$ & $-0,035$ & 0,238 & & \\
\hline American Banknote & $27 / 04 / 06$ & 0,059 & $-0,059$ & $-0,236$ & 0,065 & 0,135 & & & $-0,019$ & $-0,048$ & $-0,144$ & $-0,018$ & 0,230 & & \\
\hline CSU CardSystem & 02/05/06 & $-0,028$ & $-0,217$ & $-0,256$ & $-0,292$ & $-0,362$ & & & 0,021 & $-0,051$ & $-0,078$ & 0,012 & 0,244 & & \\
\hline Lupatech & 15/05/06 & 0,060 & $-0,070$ & 0,045 & 0,257 & 0,863 & & & $-0,027$ & $-0,158$ & $-0,140$ & 0,018 & 0,250 & & \\
\hline GP Investments & $01 / 06 / 06$ & 0,001 & $-0,008$ & 0,065 & 0,313 & 1,172 & & & 0,026 & 0,021 & 0,007 & 0,133 & 0,450 & & \\
\hline Datasul & 02/06/06 & $-0,067$ & 0,000 & $-0,042$ & 0,072 & 0,373 & & & \begin{tabular}{|l|}
0,007 \\
\end{tabular} & $-0,005$ & $-0,006$ & 0,135 & 0,413 & & \\
\hline Média & & 0,083 & 0,060 & 0,094 & 0,306 & 0,564 & 0,573 & 0,533 & 0,001 & 0,020 & 0,044 & 0,143 & 0,353 & 0,418 & 0,456 \\
\hline Mediana & & 0,063 & 0,055 & 0,065 & 0,257 & 0,461 & 0,613 & 0,577 & 0,003 & 0,023 & 0,043 & 0,080 & 0,368 & 0,397 & 0,451 \\
\hline
\end{tabular}


Tabela A.5

AR (adjusted-return)

\begin{tabular}{|c|c|c|c|c|c|c|c|c|}
\hline \multicolumn{9}{|c|}{$\mathrm{AR}$} \\
\hline Empresa & Data da IPO & 1 dia & 1 mês & 2 meses & 6 meses & 12 meses & 24 meses & 36 meses \\
\hline Natura & $26 / 05 / 04$ & 0,1443 & 0,2193 & 0,3719 & 0,4689 & 0,6378 & 0,3925 & 0,1094 \\
\hline Gol & $24 / 06 / 04$ & 0,0550 & $-0,0693$ & $-0,1446$ & 0,2862 & $-0,0038$ & 0,2853 & $-0,0939$ \\
\hline ALL America Latina & $25 / 06 / 04$ & 0,1288 & 0,1060 & 0,1834 & 0,3246 & $-0,0854$ & 0,2954 & 0,2135 \\
\hline CPFL Energia & $29 / 09 / 04$ & $-0,0032$ & $-0,0670$ & $-0,1334$ & $-0,1431$ & $-0,0192$ & 0,0274 & \\
\hline Grendene & $29 / 10 / 04$ & 0,1126 & 0,0109 & $-0,1380$ & $-0,5355$ & $-0,8165$ & $-0,5702$ & \\
\hline$\overline{D a s a}$ & $19 / 11 / 04$ & 0,2007 & 0,0845 & 0,2284 & 0,4201 & 0,6303 & 0,1479 & \\
\hline Porto Seguro & $22 / 11 / 04$ & 0,0580 & $-0,0849$ & 0,0974 & 0,0764 & 0,0944 & 0,4040 & \\
\hline Renar Macas & $28 / 02 / 05$ & 0,0253 & $-0,1490$ & $-0,2095$ & $-0,5260$ & $-1,0007$ & $-0,5786$ & \\
\hline Submarino & $30 / 03 / 05$ & $-0,0196$ & $-0,1714$ & $-0,1568$ & 0,0717 & 0,8812 & 0,5473 & \\
\hline$\overline{\text { Localiza }}$ & $23 / 05 / 05$ & 0,0123 & 0,0091 & 0,1849 & 0,8816 & 1,9058 & 0,9995 & \\
\hline Energias BR & $13 / 07 / 05$ & 0,1018 & 0,3019 & 0,1840 & 0,2663 & 0,1455 & 0,0060 & \\
\hline OHL Brasil & $15 / 07 / 05$ & 0,0324 & $-0,0282$ & 0,1214 & 0,1157 & $-0,1830$ & $-0,0985$ & \\
\hline Cosan & $18 / 11 / 05$ & 0,1583 & 0,3334 & 0,5283 & 1,7728 & 0,9978 & & \\
\hline Universo Online & $16 / 12 / 05$ & 0,1609 & $-0,0444$ & $-0,3141$ & $-0,4054$ & $-0,7048$ & & \\
\hline $\begin{array}{l}\text { Vivax } \\
\end{array}$ & $08 / 02 / 06$ & 0,0520 & 0,0015 & 0,0105 & $-0,1615$ & $\begin{array}{l}-0,0378 \\
\end{array}$ & & \\
\hline Copasa MG & $08 / 02 / 06$ & 0,1113 & 0,0809 & 0,1143 & 0,3039 & 0,6225 & & \\
\hline Gafisa & $17 / 02 / 06$ & 0,2901 & 0,3139 & 0,1395 & 0,3942 & 0,7031 & & \\
\hline Company & $02 / 03 / 06$ & 0,1910 & 0,1395 & $-0,0327$ & $-0,0676$ & 0,3098 & & \\
\hline Totvs & $09 / 03 / 06$ & 0,0875 & 0,1292 & 0,1595 & 0,2673 & 0,5484 & & \\
\hline Equatorial & $03 / 04 / 06$ & 0,1477 & $-0,0200$ & 0,1077 & 0,1386 & 0,0664 & & \\
\hline American Banknote & $27 / 04 / 06$ & 0,0774 & $-0,0111$ & $-0,0921$ & 0,0828 & $-0,0945$ & & \\
\hline CSU CardSystem & $02 / 05 / 06$ & $-0,0484$ & $-0,1660$ & $-0,1772$ & $-0,3038$ & $-0,6056$ & & \\
\hline Lupatech & $15 / 05 / 06$ & 0,0869 & 0,0876 & 0,1852 & 0,2393 & 0,6126 & & \\
\hline GP Investments & $01 / 06 / 06$ & $-0,0251$ & $-0,0288$ & 0,0580 & 0,1803 & 0,7225 & & \\
\hline Datasul & $02 / 06 / 06$ & $-0,0732$ & 0,0052 & $-0,0359$ & $-0,0624$ & $-0,0403$ & & \\
\hline Média & & 0,0826 & 0,0393 & 0,0496 & 0,1634 & 0,2115 & 0,1548 & 0,0763 \\
\hline Mediana & & 0,0869 & 0,0052 & 0,0974 & 0,1386 & 0,0944 & 0,2166 & 0,1094 \\
\hline
\end{tabular}


Tabela A.6

AR (retorno ajustado pelo risco sistêmico)

\begin{tabular}{|c|c|c|c|c|}
\hline Empresa & Data da IPO & 12 meses & 24 meses & 36 meses \\
\hline Natura & $26 / 05 / 04$ & $63,78 \%$ & $18,05 \%$ & $-26,48 \%$ \\
\hline Gol & $24 / 06 / 04$ & $-10,67 \%$ & $0,44 \%$ & $-49,90 \%$ \\
\hline ALL America Latina & $25 / 06 / 04$ & $-19,58 \%$ & $29,54 \%$ & $25,86 \%$ \\
\hline CPFL Energia & $29 / 09 / 04$ & $2,88 \%$ & $-3,90 \%$ & \\
\hline Grendene & $29 / 10 / 04$ & $-106,01 \%$ & $-75,02 \%$ & \\
\hline Dasa & $19 / 11 / 04$ & $25,25 \%$ & $-4,46 \%$ & \\
\hline Porto Seguro & $22 / 11 / 04$ & $22,71 \%$ & $44,32 \%$ & \\
\hline Renar Macas & $28 / 02 / 05$ & $-118,35 \%$ & $-69,12 \%$ & \\
\hline Submarino & $30 / 03 / 05$ & $71,54 \%$ & $28,29 \%$ & \\
\hline Localiza & $23 / 05 / 05$ & $167,62 \%$ & $60,14 \%$ & \\
\hline Energias BR & $13 / 07 / 05$ & $5,55 \%$ & $-36,79 \%$ & \\
\hline OHL Brasil & $15 / 07 / 05$ & $-79,08 \%$ & $-67,70 \%$ & \\
\hline Cosan & $18 / 11 / 05$ & $60,77 \%$ & & \\
\hline Universo Online & $16 / 12 / 05$ & $-101,41 \%$ & & \\
\hline Vivax & $08 / 02 / 06$ & $-24,90 \%$ & & \\
\hline Copasa MG & $08 / 02 / 06$ & $52,87 \%$ & & \\
\hline Gafisa & $17 / 02 / 06$ & $45,01 \%$ & & \\
\hline Company & $02 / 03 / 06$ & $2105 \%$ & & \\
\hline Totvs & $09 / 03 / 06$ & $42,75 \%$ & & \\
\hline Equatorial & $03 / 04 / 06$ & $-5,25 \%$ & & \\
\hline American Banknote & $27 / 04 / 06$ & $-16,34 \%$ & & \\
\hline CSU CardSystem & $02 / 05 / 06$ & $-53,24 \%$ & & \\
\hline Lupatech & $15 / 05 / 06$ & $51,24 \%$ & & \\
\hline GP Investments & $01 / 06 / 06$ & $81,24 \%$ & & \\
\hline Datasul & $02 / 06 / 06$ & $-28,83 \%$ & & \\
\hline Média & & $6,02 \%$ & $-3,05 \%$ & $-2,02 \%$ \\
\hline Mediana & & $5,55 \%$ & $-1,73 \%$ & $-26,48 \%$ \\
\hline
\end{tabular}


Tabela A.7

MAAR (market-adjusted abnormal returns)

\begin{tabular}{|c|c|c|c|c|c|c|c|c|}
\hline \multicolumn{9}{|c|}{ MAAR } \\
\hline Empresa & Data da IPO & 1 dia & 1 mês & 2 meses & 6 meses & 12 meses & 24 meses & 36 meses \\
\hline Natura & $26 / 05 / 04$ & 0,1426 & 0,2040 & 0,3391 & 0,3466 & 0,4453 & 0,2565 & 0,0745 \\
\hline Gol & $24 / 06 / 04$ & 0,0551 & $-0,0679$ & $-0,1297$ & 0,2119 & $-0,0028$ & 0,2036 & $\begin{array}{l}-0,0647 \\
\end{array}$ \\
\hline ALL America Latina & $25 / 06 / 04$ & 0,1284 & 0,1037 & 0,1629 & 0,2400 & $-0,0624$ & 0,2107 & 0,1472 \\
\hline CPFL Energia & $29 / 09 / 04$ & $-0,0032$ & $-0,0652$ & $-0,1241$ & $-0,1215$ & $-0,0129$ & 0,0206 & \\
\hline Grendene & $29 / 10 / 04$ & 0,1117 & 0,0103 & $-0,1204$ & $-0,4862$ & $-0,5808$ & $-0,4192$ & \\
\hline Dasa & $19 / 11 / 04$ & 0,2009 & 0,0788 & 0,2142 & 0,3891 & 0,4440 & 0,1068 & \\
\hline Porto Seguro & $22 / 11 / 04$ & 0,0576 & $-0,0779$ & 0,0912 & 0,0724 & 0,0655 & 0,2901 & \\
\hline Renar Macas & $28 / 02 / 05$ & 0,0257 & $-0,1612$ & $-0,2473$ & $-0,5255$ & $-0,6869$ & $-0,4516$ & \\
\hline Submarino & $30 / 03 / 05$ & $-0,0192$ & $-0,1798$ & $-0,1607$ & 0,0564 & 0,5675 & 0,3973 & \\
\hline Localiza & $23 / 05 / 05$ & 0,0125 & 0,0088 & 0,1774 & 0,6435 & 1,2107 & 0,6674 & \\
\hline Energias BR & $13 / 07 / 05$ & 0,1008 & 0,2749 & 0,1585 & 0,1801 & 0,1003 & 0,0039 & \\
\hline OHL Brasil & $15 / 07 / 05$ & 0,0331 & $-0,0259$ & 0,1037 & 0,0774 & $-0,1302$ & $-0,0646$ & \\
\hline Cosan & $18 / 11 / 05$ & 0,1583 & 0,3138 & 0,4477 & 1,4421 & 0,7366 & & \\
\hline Universo Online & $16 / 12 / 05$ & 0,1599 & $-0,0391$ & $-0,2650$ & $-0,3882$ & $-0,5245$ & & \\
\hline$\overline{\text { Vivax }}$ & $08 / 02 / 06$ & 0,0523 & 0,0015 & 0,0101 & $-0,1580$ & $-0,0307$ & & \\
\hline Copasa MG & $08 / 02 / 06$ & 0,1119 & 0,0805 & 0,1102 & 0,2973 & 0,5042 & & \\
\hline Gafisa & $17 / 02 / 06$ & 0,2888 & 0,3149 & 0,1401 & 0,3994 & 0,5807 & & \\
\hline Company & $02 / 03 / 06$ & 0,1916 & 0,1425 & $-0,0317$ & $-0,0699$ & 0,2841 & & \\
\hline Totvs & $09 / 03 / 06$ & 0,0897 & 0,1252 & 0,1412 & 0,2763 & 0,4564 & & \\
\hline Equatorial & $03 / 04 / 06$ & 0,1445 & $-0,0186$ & 0,1101 & 0,1437 & 0,0536 & & \\
\hline American Banknote & $27 / 04 / 06$ & 0,0789 & $-0,0117$ & $-0,1077$ & 0,0843 & $-0,0769$ & & \\
\hline CSU CardSystem & $02 / 05 / 06$ & $-0,0474$ & $-0,1749$ & $-0,1922$ & $-0,3002$ & $-0,4868$ & & \\
\hline Lupatech & $15 / 05 / 06$ & 0,0893 & 0,1041 & 0,2152 & 0,2352 & 0,4899 & & \\
\hline GP Investments & $01 / 06 / 06$ & $-0,0244$ & $-0,0282$ & 0,0576 & 0,1592 & 0,4984 & & \\
\hline Datasul & $02 / 06 / 06$ & $-0,0728$ & 0,0052 & $-0,0361$ & $-0,0550$ & $-0,0285$ & & \\
\hline Média & & 0,0827 & 0,0367 & 0,0426 & 0,1260 & 0,1526 & 0,1018 & 0,0523 \\
\hline Mediana & & 0,0893 & 0,0052 & 0,0912 & 0,1437 & 0,0655 & 0,1552 & 0,0745 \\
\hline
\end{tabular}


Tabela A.8

BHAR (buy-and-hold adjusted return)

\begin{tabular}{|c|c|c|c|c|c|}
\hline & & BHAR & & & \\
\hline Empresa & Data da IPO & 6 meses & 12 meses & 24 meses & 36 meses \\
\hline Natura & $26 / 05 / 04$ & 0,1785 & 0,2649 & 0,0997 & $-0,0051$ \\
\hline Gol & $24 / 06 / 04$ & 0,1486 & $-0,0549$ & 0,1408 & $-0,0100$ \\
\hline ALL America Latina & $25 / 06 / 04$ & 0,0988 & $-0,1691$ & 0,0729 & 0,0014 \\
\hline CPFL Energia & $29 / 09 / 04$ & $-0,1187$ & $-0,0098$ & 0,0238 & \\
\hline Grendene & $29 / 10 / 04$ & $\begin{array}{l}-0,5378 \\
\end{array}$ & $-0,6229$ & $-0,4775$ & \\
\hline Dasa & $19 / 11 / 04$ & 0,1567 & 0,2024 & $-0,0783$ & \\
\hline Porto Seguro & $22 / 11 / 04$ & 0,0139 & 0,0074 & 0,2198 & \\
\hline Renar Macas & $28 / 02 / 05$ & $-0,5374$ & $-0,6947$ & $-0,4653$ & \\
\hline Submarino & $30 / 03 / 05$ & 0,0771 & 0,5982 & 0,4246 & \\
\hline Localiza & $23 / 05 / 05$ & 0,6233 & 1,1835 & 0,6469 & \\
\hline Energias BR & $13 / 07 / 05$ & 0,0720 & $-0,0005$ & $-0,0881$ & \\
\hline OHL Brasil & $15 / 07 / 05$ & 0,0429 & $-0,1581$ & $-0,0945$ & \\
\hline Cosan & $18 / 11 / 05$ & 1,1083 & 0,4992 & & \\
\hline Universo Online & $16 / 12 / 05$ & $-0,4725$ & $-0,5901$ & & \\
\hline Vivax & $08 / 02 / 06$ & $-0,1998$ & $-0,0788$ & & \\
\hline Copasa MG & $08 / 02 / 06$ & 0,1668 & 0,3528 & & \\
\hline Gafisa & $17 / 02 / 06$ & 0,0859 & 0,2265 & & \\
\hline Company & $02 / 03 / 06$ & $-0,2195$ & 0,0776 & & \\
\hline Totvs & $09 / 03 / 06$ & 0,1712 & 0,3365 & & \\
\hline Equatorial & $03 / 04 / 06$ & $\begin{array}{l}-0,0008 \\
\end{array}$ & $-0,0795$ & & \\
\hline American Banknote & $27 / 04 / 06$ & 0,0050 & $-0,1444$ & & \\
\hline CSU CardSystem & $02 / 05 / 06$ & $-0,2653$ & $-0,4613$ & & \\
\hline Lupatech & $15 / 05 / 06$ & 0,1339 & 0,3678 & & \\
\hline GP Investments & $01 / 06 / 06$ & 0,1882 & 0,5359 & & \\
\hline Datasul & $02 / 06 / 06$ & 0,0192 & 0,0477 & & \\
\hline Média & & 0,0375 & 0,0655 & 0,0354 & $-0,0046$ \\
\hline Mediana & & 0,0720 & 0,0074 & 0,0483 & $-0,0051$ \\
\hline
\end{tabular}


Tabela A.9

MMAR(monthly market-adjusted return)

\begin{tabular}{|c|c|c|c|c|c|c|c|c|}
\hline \multicolumn{9}{|c|}{ MMAR } \\
\hline Empresa & Data da IPO & 1 dia & 1 mês & 2 meses & 6 meses & 12 meses & 24 meses & 36 meses \\
\hline Natura & $26 / 05 / 04$ & 0,1426 & 0,2040 & 0,1695 & 0,0578 & 0,0371 & 0,0107 & 0,0021 \\
\hline Gol & $24 / 06 / 04$ & 0,0551 & $-0,0679$ & $-0,0648$ & 0,0353 & $-0,0002$ & 0,0085 & $-0,0018$ \\
\hline ALL America Latina & $25 / 06 / 04$ & 0,1284 & 0,1037 & 0,0814 & 0,0400 & $-0,0052$ & 0,0088 & 0,0041 \\
\hline CPFL Energia & $29 / 09 / 04$ & $-0,0032$ & $-0,0652$ & $-0,0620$ & $-0,0203$ & $-0,0011$ & 0,0009 & \\
\hline Grendene & $29 / 10 / 04$ & 0,1117 & 0,0103 & $-0,0602$ & $-0,0810$ & $-0,0484$ & $-0,0175$ & \\
\hline Dasa & $19 / 11 / 04$ & 0,2009 & 0,0788 & 0,1071 & 0,0648 & 0,0370 & 0,0044 & \\
\hline Porto Seguro & $22 / 11 / 04$ & 0,0576 & $-0,0779$ & 0,0456 & 0,0121 & 0,0055 & 0,0121 & \\
\hline Renar Macas & $28 / 02 / 05$ & 0,0257 & $-0,1612$ & $-0,1237$ & $-0,0876$ & $-0,0572$ & $-0,0188$ & \\
\hline Submarino & $30 / 03 / 05$ & $-0,0192$ & $-0,1798$ & $-0,0804$ & 0,0094 & 0,0473 & 0,0166 & \\
\hline Localiza & $23 / 05 / 05$ & 0,0125 & 0,0088 & 0,0887 & 0,1072 & 0,1009 & 0,0278 & \\
\hline Energias BR & $13 / 07 / 05$ & 0,1008 & 0,2749 & 0,0793 & 0,0300 & 0,0084 & 0,0002 & \\
\hline OHL Brasil & $15 / 07 / 05$ & 0,0331 & $-0,0259$ & 0,0519 & 0,0129 & $-0,0109$ & $-0,0027$ & \\
\hline Cosan & $18 / 11 / 05$ & 0,1583 & 0,3138 & 0,2238 & 0,2404 & 0,0614 & & \\
\hline Universo Online & $16 / 12 / 05$ & 0,1599 & $-0,0391$ & $-0,1325$ & $-0,0647$ & $-0,0437$ & & \\
\hline Vivax & $08 / 02 / 06$ & 0,0523 & 0,0015 & 0,0051 & $-0,0263$ & $-0,0026$ & & \\
\hline Copasa MG & $08 / 02 / 06$ & 0,1119 & 0,0805 & 0,0551 & 0,0496 & 0,0420 & & \\
\hline Gafisa & $17 / 02 / 06$ & 0,2888 & 0,3149 & 0,0701 & 0,0666 & 0,0484 & & \\
\hline Company & $02 / 03 / 06$ & 0,1916 & 0,1425 & $-0,0158$ & $-0,0117$ & 0,0237 & & \\
\hline Totvs & $09 / 03 / 06$ & 0,0897 & 0,1252 & 0,0706 & 0,0460 & 0,0380 & & \\
\hline Equatorial & $03 / 04 / 06$ & 0,1445 & $-0,0186$ & 0,0551 & 0,0239 & 0,0045 & & \\
\hline American Banknote & $27 / 04 / 06$ & 0,0789 & $-0,0117$ & $-0,0538$ & 0,0140 & $-0,0064$ & & \\
\hline CSU CardSystem & $02 / 05 / 06$ & $-0,0474$ & $-0,1749$ & $-0,0961$ & $-0,0500$ & $-0,0406$ & & \\
\hline Lupatech & $15 / 05 / 06$ & 0,0893 & 0,1041 & 0,1076 & 0,0392 & 0,0408 & & \\
\hline GP Investments & $01 / 06 / 06$ & $-0,0244$ & $-0,0282$ & 0,0288 & 0,0265 & 0,0415 & & \\
\hline Datasul & $02 / 06 / 06$ & $-0,0728$ & 0,0052 & $-0,0181$ & $\begin{array}{l}-0,0092 \\
\end{array}$ & $-0,0024$ & & \\
\hline Média & & 0,0827 & 0,0367 & 0,0213 & 0,0210 & 0,0127 & 0,0042 & 0,0015 \\
\hline Mediana & & 0,0893 & 0,0052 & 0,0456 & 0,0239 & 0,0055 & 0,0065 & 0,0021 \\
\hline
\end{tabular}

Tabela A.10

Evidência internacional de desempenho de IPOs no curto prazo

\begin{tabular}{lccc}
\hline \multicolumn{1}{c}{ País } & Tamanho da Amostra & Período & Retorno Médio \\
\hline Austrália & 266 & $1976-1989$ & $11,90 \%$ \\
\hline Áustria & 67 & $1964-1996$ & $6,50 \%$ \\
\hline Brasil & 62 & $1979-1990$ & $78,50 \%$ \\
\hline Canada & 258 & $1971-1992$ & $5,40 \%$ \\
\hline Chile & 19 & $1982-1990$ & $16,30 \%$ \\
\hline Finlândia & 85 & $1984-1992$ & $9,60 \%$ \\
\hline Alemanha & 170 & $1978-1992$ & $10,90 \%$ \\
\hline Japão & 975 & $1970-1996$ & $24,00 \%$ \\
\hline Coréia & 347 & $1980-1990$ & $78,10 \%$ \\
\hline Nova Zelandia & 149 & $1979-1991$ & $28,80 \%$ \\
\hline Suécia & 213 & $1970-1991$ & $39,00 \%$ \\
\hline Reino Unido & 2133 & $1959-1990$ & $12,00 \%$ \\
\hline Estados Unidos & 13308 & $1960-1996$ & $15,80 \%$ \\
\hline \multicolumn{3}{l}{} \\
\hline Média & & \\
\hline \multicolumn{3}{l}{} \\
\hline Mediana & & \\
\hline
\end{tabular}


Tabela A.11

Evidência internacional de desempenho de IPOs no longo prazo

\begin{tabular}{lccc}
\hline \multicolumn{1}{c}{ País } & Tamanho da Amostra & Período & Retorno Médio \\
\hline Austrália & 266 & $1976-1989$ & $-46,50 \%$ \\
\hline Austria & 67 & $1964-1996$ & $-27,30 \%$ \\
\hline Brasil & 62 & $1979-1990$ & $-47,00 \%$ \\
\hline Canada & 445 & $1991-1998$ & $-16,86 \%$ \\
\hline Chile & 19 & $1982-1990$ & $-23,70 \%$ \\
\hline Finlândia & 85 & $1984-1992$ & $-21,10 \%$ \\
\hline Alemanha & 170 & $1978-1992$ & $-12,10 \%$ \\
\hline Japão & 975 & $1970-1996$ & $-27,00 \%$ \\
\hline Coréia & 347 & $1980-1990$ & $2,00 \%$ \\
\hline Nova Zelandia & 143 & $1979-1987$ & $-10,00 \%$ \\
\hline Suécia & 162 & $1980-1990$ & $1,20 \%$ \\
\hline Reino Unido & 712 & $1980-1988$ & $-8,10 \%$ \\
\hline Estados Unidos & 4753 & $1970-1990$ & $-20,00 \%$ \\
\hline \multicolumn{4}{l}{} \\
\hline Média & & $-19,73 \%$ \\
\hline & & \\
\hline Mediana & & $-20,00 \%$ \\
\hline
\end{tabular}

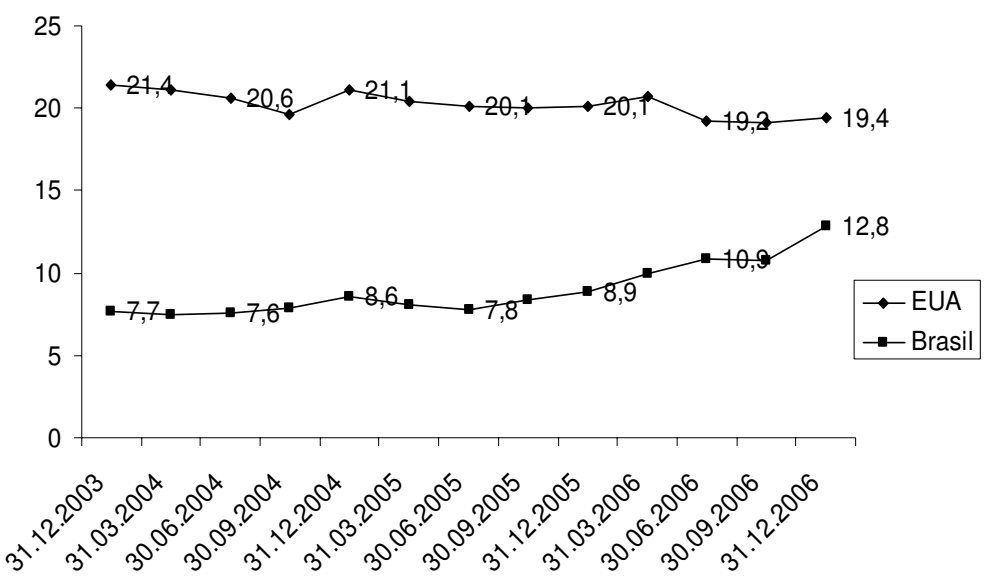

Figura A.1

Mediana do múltiplo P/L

* O cálculo não considerou a participação de cada ativo no mercado imobiliário 


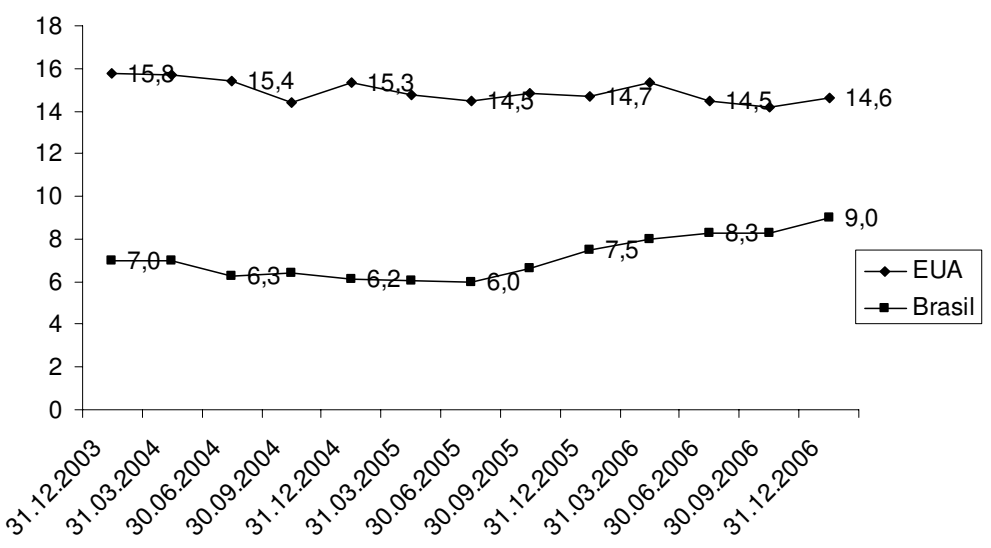

Figura A.2

Mediana do EV/EBIT

O cálculo não considerou a participação de cada ativo no mercado imobiliário

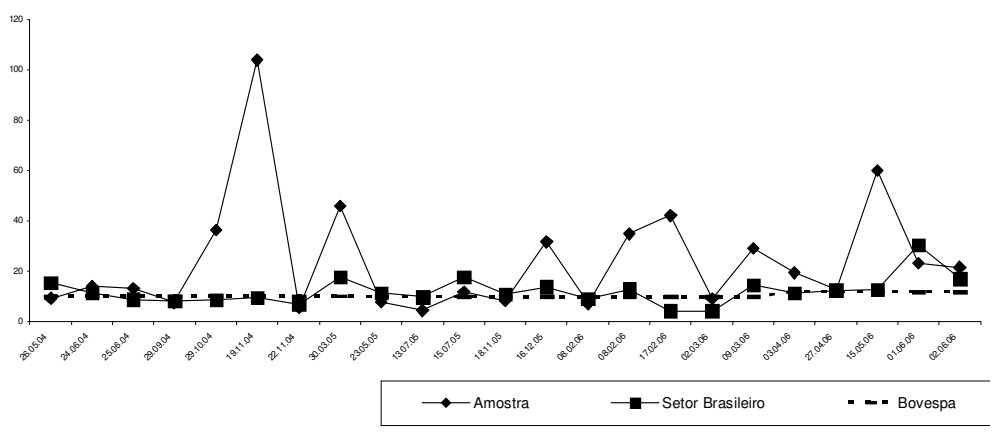

Figura A.3

$\mathrm{P} / \mathrm{L}$ da amostra (múltiplos futuros) 


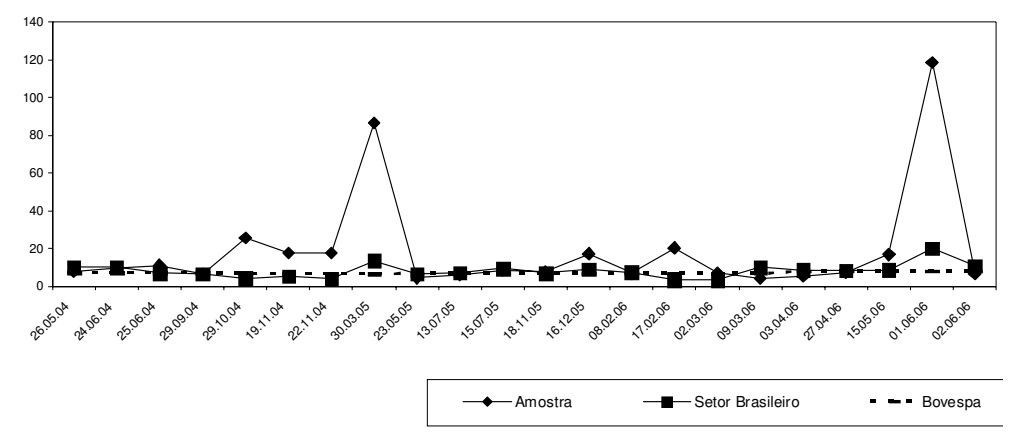

Figura A.4

EV/EBIT da amostra (múltiplos futuros) 